\title{
Human Serine Racemase: Key Residues/Active Site Motifs and Their Relation to Enzyme Function
}

\author{
Danielle L. Graham, Matthew L. Beio, David L. Nelson and David B. Berkowitz* \\ Department of Chemistry, University of Nebraska-Lincoln, Lincoln, NE, United States
}

Serine racemase (SR) is the first racemase enzyme to be identified in human biology and converts L-serine to D-serine, an important neuronal signaling molecule that serves as a co-agonist of the NMDA ( $\mathrm{N}$-methyl-D-aspartate) receptor. This overview describes key molecular features of the enzyme, focusing on the side chains and binding motifs that control PLP (pyridoxal phosphate) cofactor binding as well as activity modulation through the binding of both divalent cations and ATP, the latter showing allosteric modulation. Discussed are catalytically important residues in the active site including K56 and S84-the si- and re-face bases, respectively, - and R135, a residue that appears to play a critical role in the binding of both negatively charged alternative substrates and inhibitors. The interesting bifurcated mechanism followed by this enzyme whereby substrate L-serine can be channeled either into D-serine (racemization pathway) or into pyruvate ( $\beta$-elimination pathway) is discussed extensively, as are studies that focus on a key loop region (the so-called "triple serine loop"), the modification of which can be used to invert the normal in vitro preference of this enzyme for the latter pathway over the former. The possible cross-talk between the PLP enzymes hSR and hCBS (human cystathionine $\beta$-synthase) is discussed, as the former produces D-serine and the latter produces $\mathrm{H}_{2} \mathrm{~S}$, both of which stimulate the NMDAR and both of which have been implicated in neuronal infarction pursuant to ischemic stroke. Efforts to gain a more complete mechanistic understanding of these PLP enzymes are expected to provide valuable insights for the development of specific small molecule modulators of these enzymes as tools to study their roles in neuronal signaling and in modulation of NMDAR function.

Keywords: D-serine, pyridoxal phosphate (PLP), serine racemase, racemization, elimination, mechanism, ATP, allosteric activation/regulation

\section{INTRODUCTION}

Pyridoxal phosphate (PLP) enzymes have been extensively studied owing to interest in both the molecular details of their chemistry and the physiologic importance of the reactions that they catalyze, particularly in the area of neuroactive amine homeostasis (Walsh, 1979; Toney, 2005). This review will focus on key residues, binding sites and catalytically important motifs of human serine racemase, and its mammalian counterparts. In the literature to date, there are several reviews on topics such as the importance of D-serine and serine racemase in glial neurotransmission (Mothet, 2008; Wolosker, 2011, 2018; Wolosker and Mori, 2012; Wolosker et al., 2016) and in neurodegeneration (Campanini et al., 2013; Coyle and Balu, 2018). In addition, recent reviews 
by Mozzarelli (Raboni et al., 2019) and by Mori (Mori, 2014) discuss the SR energy landscape and mechanism in the context of structure. The current review also builds upon previous reviews that discuss inhibition of hSR (Jirásková-Vanícková et al., 2011), in focusing upon key residues and structural motifs to consider in generating future inhibitors.

Traditionally thought to be restricted almost exclusively to the domain of bacterial cell wall biosynthesis, D-amino acids are now clearly seen as playing important and as yet incompletely understood roles in human biology, particularly in neuronal signaling (Wolosker et al., 2008; Li et al., 2017; Weatherly et al., 2017; Du et al., 2018). Although the receptor is named after its ability to bind N-methyl-D-aspartate (NMDA), L-glutamate is the primary agonist of the NMDA receptor with D-serine (D-Ser), serving as co-agonist, as illustrated in Figure 1. The NMDAR operates primarily as a ligand-gated channel that dislodges a $\mathrm{Mg}^{2+}$ or $\mathrm{Zn}^{2+}$ ion, allowing for depolarization and $\mathrm{Ca}^{2+}$ influx. $\mathrm{Ca}^{2+}$ ions are critical for synaptic plasticity and appropriate levels of each agonist are required for neuronal homeostasis and long-term potentiation (LTP) associated with learning and memory.

Whereas D-serine binds to the so-called "glycine site" of the NMDAR, it displays $>2$ orders of magnitude more potent activation of the NMDAR than glycine (Gly) itself (Berger et al., 1998; Wolosker, 2007). Perhaps the best experiments demonstrating this are elegant in vitro measurements of miniature excitatory postsynaptic currents (mEPSCs). In response to coagonist stimulation, $0.3 \mu \mathrm{M}$ D-serine produces a higher level of NMDA charge transfer than $30 \mu \mathrm{M}$ glycine (Berger et al., 1998). Consistent with these observations, the crystal structures of the NR1 subunit of the NMDAR with bound D-Ser (PDB code: 1PB8) and with bound Gly (PDB code: 1PB7) demonstrate that the former ligand engages in several additional hydrogen bonds as compared with the latter (Furukawa and Gouaux, 2003). This topic has been more extensively reviewed elsewhere (Schell, 2004). Recent reports also show that D-Ser, and not Gly, is responsible for LTP in the visual cortex (Meunier et al., 2016), and demonstrate that D-Ser concentrations in compartments of the cerebellum are much more tightly controlled than those of Gly, with the former being concentrated in the neocortex where complex thinking is taking place (Suzuki et al., 2017).

At the turn of the millennium, it was established that biosynthesis of D-Ser is mediated by a PLP-dependent serine racemase enzyme. This constituted the first known example of a mammalian racemase enzyme (Wolosker et al., 1999; De Miranda et al., 2000). Interestingly, human serine racemase (hSR) has an apparent dual role as it funnels neuronal L-serine into bifurcating pathways toward either D-Ser (racemization) or pyruvate ( $\beta$-elimination).

\section{MECHANISM}

The generally accepted mechanism by which human SR catalyzes both the racemization of L-Ser to D-Ser and the elimination of LSer to pyruvate is illustrated schematically in Figure 2. Substrate L-Ser displaces K56 via an initial transaldimination reaction to form the external aldimine. The displaced K56 residue serves as the $s i$-face base, $\alpha$-deprotonating to yield a common carbanionic or quinonoid intermediate (see Discussion below). This is the point at which the path bifurcates with $r e$-face reprotonation by S84 giving the racemization product, D-Ser, or with expulsion of the $\beta$-OH-leaving group, presumably following protonation, giving rise to an enamine that eventually is released as pyruvate, the $\beta$-elimination product. The wt-hSR enzyme displays an $\sim 4$ fold preference for the $\beta$-elimination pathway over racemization under in vitro steady-state enzyme kinetic conditions (Nelson et al., 2017). However, Toney and co-workers showed that this ratio can be significantly altered by selected mutations (Foltyn et al., 2005) as will be discussed. Moreover, given the number of important protein-protein interactions (PPI) that have been implicated for hSR in vivo (Fujii et al., 2006; Baumgart et al., 2007; Hikida et al., 2008; Ma et al., 2013, 2014), one must consider that these may influence hSR activity and the racemization to $\beta$-elimination ratio seen in vivo as well.

\section{SEQUENCE OVERVIEW}

A global overview of SR primary structure with an eye toward highlighting key functional domains is presented in Figure 3. This review will discuss conserved motifs displayed there, including all the elements of the PLP binding pocket-the essential lysine residue, the tetraglycine loop for phosphate binding (Smith et al., 2010), the H-bond donor for the PLP ring nitrogen and the edge-to-face $\pi-\pi$ interaction that serves to anchor the pyridine ring (Wang and Barger, 2012). The enzyme is stimulated by both divalent metal cation binding and ATP binding, each with established contact residues, with good evidence for allostery in the case of the nucleotide binding site. Finally, an interesting "triple Ser loop" is present that appears to have significant influence on the bifurcation, i.e., L-serine racemization vs. $\beta$-elimination activity.

\section{DIVALENT METAL BINDING SITE}

The importance of divalent metal cation binding to hSR was first reported, in parallel, by the laboratories of Wolosker (De Miranda et al., 2002) and of Cook (Cook et al., 2002). The latter group performed the most extensive study of divalent cations, finding that $\mathrm{Mn}^{2+}$ leads to the highest increase in activity of the enzyme $(153 \% @ 10 \mu \mathrm{M})$, followed by $\mathrm{Ca}^{2+}(134 \% @ 1 \mathrm{mM})$ and $\mathrm{Mg}^{2+}(112 \% @ 10 \mu \mathrm{M})$ relative to the purified hSR without divalent cation supplementation. The effect of divalent metal identity upon activity does not appear to be due to major structural changes, as evidenced by circular dichroism studies. Smith et al. have deposited the coordinates of several mammalian SR crystal structures including PDB code: 3L6B displayed in Figure 4A, a structure that highlights the formally octahedral divalent metal $\left(\mathrm{Mn}^{2+}\right)$-coordination sphere involving residues E210 and D216 ( 2.1 A metal-ligand bond lengths), an amide carbonyl and three water molecules. A similar divalent metal coordination environment is seen in the S. pombe SR enzyme (PDB code: 1WTC). 


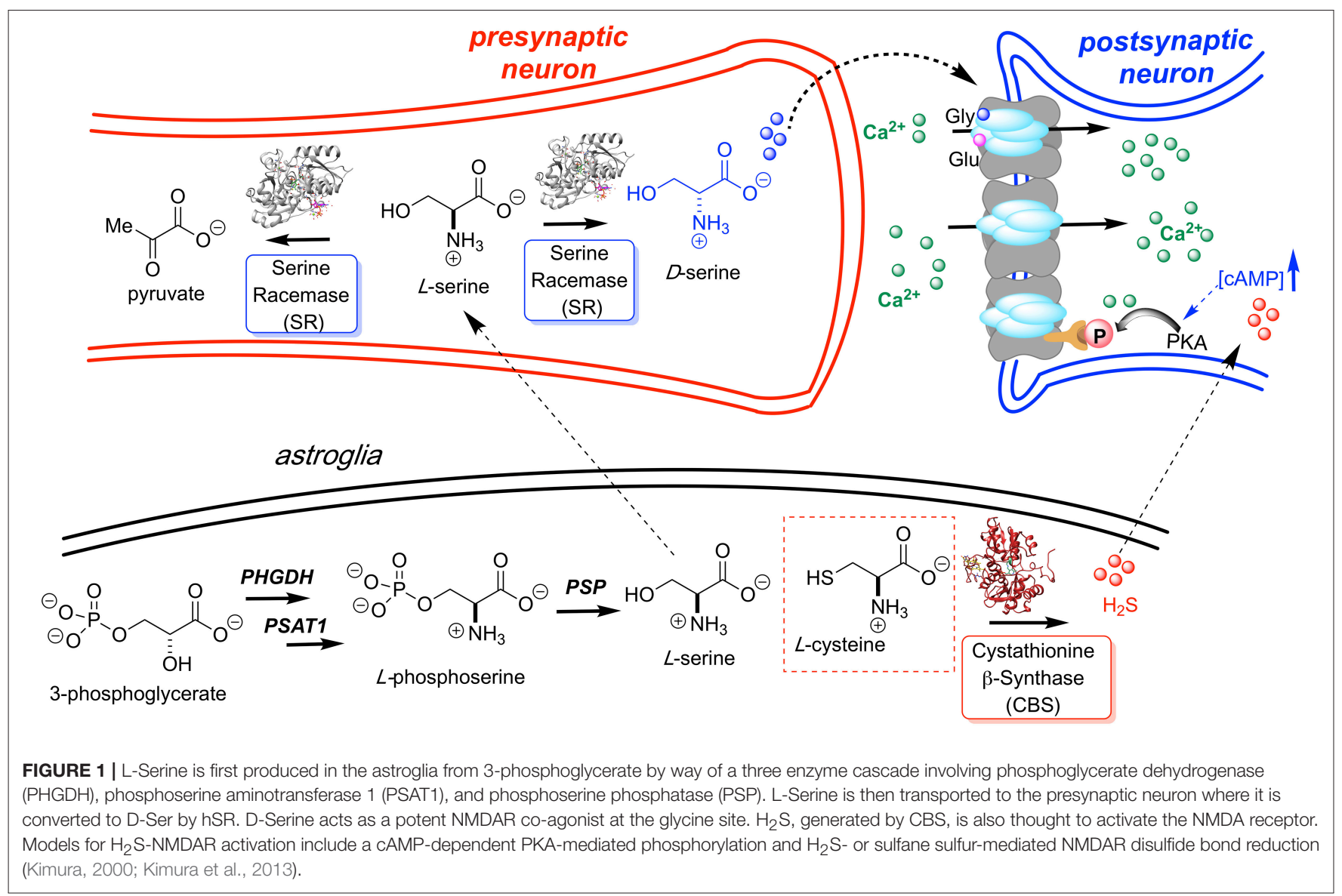

\section{ATP BINDING SITE}

Of the crystal structures currently available for SR, the ATPbinding site is best seen in the Schizosaccharomyces pombe serine racemase (SpSR) structure (1WTC) that features a bound AMPPCP ligand, a hydrolytically stable $\beta, \gamma-\mathrm{CH}_{2}$-phosphonate analog of ATP (Figure 4B). In this structure, residues K52 and N25 coordinate to the terminal phosphonate group and a $\mathrm{Mg}^{2+}$ ion bridges across the $\beta, \gamma$-phosphono groups. Tyrosine- 119 appears to be engaged in hydrogen bonding interactions with the proximal phosphate, and Asn311 appears to be engaged in a similar H-bond with the 3'-hydroxyl group of the ribose.

It is well-known that ATP-binding leads to enhanced catalytic activity for SR; an overlay of the ATP-free structure (e.g., 3L6B) with the ATP bound structure (1WTC) provides evidence that this amounts to allosteric activation (Figure 4C). Specifically, it has been argued that allostery arises through an extensive hydrogen binding network (T52, N86, Q89, E283, N316) connecting the ATP ribose 3'-hydroxyl group to the active site (T52 corresponds to M53 in SpSR). Similarly, this hydrogen binding network is predominantly conserved within close evolutionary homologs serine dehydratase $(\mathrm{SDH})$ and threonine deaminase. By aligning 186 sequences, Mozzarelli and co-workers found that the T52 position showed the highest variability while Q89 is conserved in enzymes that are allosterically regulated by nucleotides (i.e., hSR, spSR, threonine deaminases) (Canosa et al., 2018). On the other hand, Hordeum vulgare SR and SDH have either an alanine or methionine at this position and are not regulated by ATP.

Upon mutation of the Q89 residue to either a methionine or an alanine, ATP activation is reduced from a 7 -fold increase in the wt-enzyme to only 4-fold and 2-fold for the Q89M and Q89A mutants, respectively (Canosa et al., 2018). Moreover, this effect is not due to the decrease in ATP affinity, as addition of ATP at higher concentrations still fails to show activation in the mutants. Interestingly, the Q89 mutants maintain the same activity as the wt-enzyme in the absence of ATP. Studies show that these mutants exhibit non-cooperative binding with respect to ATP. This can also be observed in the crystal structures solved to date in which two different conformations of Q89 have been observed (Figure 4). It is postulated that this residue acts as a key gating residue, playing a central role in the conformational change associated with allosteric activation of the enzyme (Canosa et al., 2018).

\section{PYRIDOXAL PHOSPHATE SITE}

\section{Phosphate Binding Pocket}

Human serine racemase displays a classical PLP binding site, including all the hallmark attributes as follows: (i) the tetraglycine loop for binding of the $5^{\prime}$-phosphate (Smith et al., 2010), (ii) $\pi$ stacking interaction to engage the pyridine ring (Smith et al., 


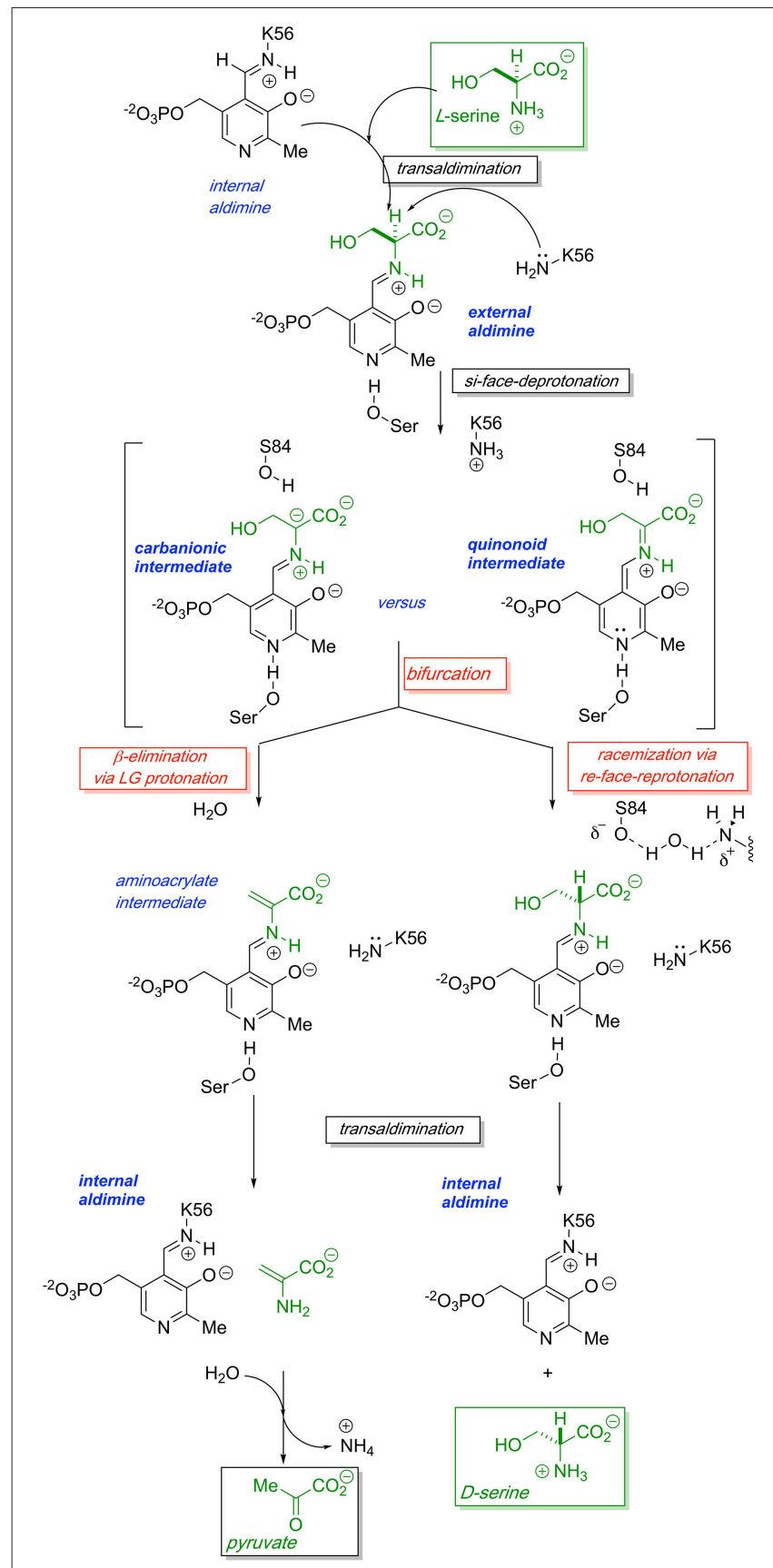

FIGURE 2 | Proposed bifurcating mechanism of hSR showing the racemization reaction vs. the competing $\beta$-elimination reaction via a common carbanionic or quinonoid intermediate.

2010), and (iii) hydrogen-bonding to the pyridine-nitrogen. The tetraglycine loop for hSR consists of a string of glycines from position 185 to 188 , each utilizing an amide $\mathrm{N}-\mathrm{H}$ to donate a hydrogen bond for phosphate binding (Smith et al., 2010). This canonical PLP enzyme feature is present in most cofactor binding sites and is quite evident in the hSR structure (Figure 5). While the PLP binding site is highly conserved across most PLP enzymes (see Figure 6) it is important to note that PLP-dependent enzymes fall into a wide range of fold types, which has been discussed nicely elsewhere (Schneider et al., 2000). For our purposes here, it is notable that PLPdependent racemases themselves fall into more than 1-fold type, with serine racemase (Yoshimura and Ito, 2014) and aspartate racemase (Takahashi, 2009) being members of the fold type II family and alanine racemase being a fold type III enzyme (Azam and Jayaram, 2016).

\section{$\pi$-Stacking}

The second key stabilizing feature often found in PLP cofactor binding sites is an aromatic amino acid side chain engaged in a favorable $\pi-\pi$ interaction with the pyridine ring. In enzymes such as serine racemase (Figure 6A) (Smith et al., 2010), aspartate racemase (Mizobuchi et al., 2017) (Figure 6C) and serine dehydratase (Figure 6D) (Wang et al., 2012), the aromatic ring for $\pi$-stacking is provided by a Phe residue immediately preceding the essential lysine in the primary sequence. The aromatic ring of this Phe side chain is engaged in an edge-to-face $\pi-\pi$-interaction at the $s i$-face of the PLP-ring. Other racemases, such as $\alpha$-amino $\varepsilon$-caprolactam racemase (Figure 6E) (Frese et al., 2017) and isoleucine 2-epimerase (Figure 6F) (Hayashi et al., 2017), utilize a tyrosine side chain for a similar edge-toface interaction.

\section{Pyridine Nitrogen}

The third feature of most PLP-binding pockets is the presence of a hydrogen bond-donating side chain that partially protonates the pyridine nitrogen in the ground state. For transaminase enzymes, this residue is generally an aspartate residue (ChanHuot et al., 2013; Fesko et al., 2018), presumably promoting formation of a quinonoid intermediate with broad charge delocalization. It has been argued that the intermediacy of such a charge-delocalized species facilitates the required azallylic isomerization (i.e., C4'-protonation) for such enzymes. For racemase enzymes, however, it is clear that such an acidic proton donor is not required. For example, perhaps the most wellstudied PLP-dependent racemase, alanine racemase, utilizes an arginine residue in this position, a weak hydrogen bond donor (Figure 6B) (Shaw et al., 1997).

A survey of current PLP-dependent racemase structures in the pdb shows that, in fact, these enzymes feature a broad range of proton donors for the pyridine ring. In aspartate racemase (Mizobuchi et al., 2017), Cys321 serves as H-bond donor (Figure 6C-PDB code: 5YBW), whereas $\alpha$-amino $\varepsilon$ caprolactam racemase (Figure 6E-PDB code: 5M46), (Frese et al., 2017) and isoleucine 2-epimerase (Figure 6F-PDB code: 5WYA) (Hayashi et al., 2017) utilize aspartatic acid residues Asp238 and Asp250, respectively, as PLP-nitrogen protonating residues. Serine racemase (Figure 6A-PDB code: 3L6B) (Smith et al., 2010) employs a serine residue, Ser313, reminiscent of $\beta$-eliminase enzymes such as tryptophan synthase or Oacetylserine sulfhydrylase (OASS). This is interesting because SR, like tryptophan synthase, catalyzes the $\beta$-elimination of water from L-serine. That said, not all $\beta$-eliminase enzymes employ a serine residue, as serine dehydratase utilizes a cysteine (Figure 6D-PDB code: 4H27) (Wang et al., 2012). 
CLUSTAL O(1.2.4) multiple sequence alignment

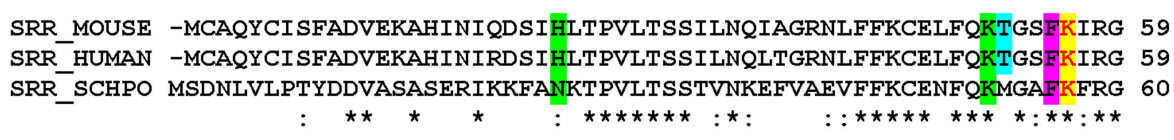

SRR_MOUSE ALNAIRGLIPDTPEEKPKAVVTHSSGNHGQALTYAAKLEGIPAYIVVPQTAPNCKKLAIQ 119 SRR HUMAN ALNAVRSLVPDALERKPKAVVTHSSGNHGQALTYAAKLEGI PAYIVVPQTAPDCKKLAIQ 119 SRR_SCHPO ALNALSQLNE---AQRKAGVLTFSSGNHAQAIALSAKILGI PAKI IMPLDAPEAKVAATK 117

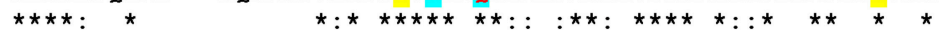

SRR MOUSE AYGASIVYCDPSDESREKVTQRIMQETEGILVHPNQEPAVIAGQGTIALEVLNQVPLVDA 179 SRR HUMAN AYGASIVYCEPSDESRENVAKRVTEETEGIMVHPNQEPAVIAGQGTIALEVLNQVPLVDA 179 SRR_SCHPO GYGGQVIMYDRYKDDREKMAKEISEREGLTI I PPYDHPHVLAGQGTAAKELFEEVGPLDA 177

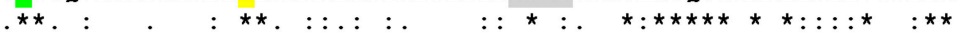

SRR_MOUSE LVVPVGGGGMVAGIAITIKALKPSVKVYAAEPSNADDCYQSKLKGELTPN-LHPPETIAD 238 SRR HUMAN LVVPVGGGGMLAGIAITVKALKPSVKVYAAEPSNADDCYQSKLKGKLMPN-LYPPETIAD 238 SRR_SCHPO LFVCLGGGGLLSGSALAARHFAPNCEVYGVEPEAGNDGQQSFRKGSIVH--IDTPKTIAD 235

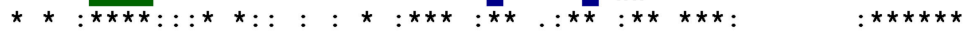

SRR MOUSE GVKS-SIGLNTWPIIRDLVDDVFTVTEDEIKYATQLVWGRMKLLIEPTAGVALAAVLSQH 297 SRR_HUMAN GVKS-SIGLNTWPIIRDLVDDIFTVTEDEIKCATQLVWERMKLLIEPTAGVGVAAVLSQH 297 SRR_SCHPO GAQTQHLGNYTFSIIKEKVDDILTVSDEELIDCLKFYAARMKIVVEPTGCLSFAAARAMK 295

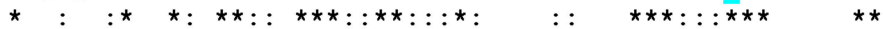

SRR MOUSE FQTVSPEVKNVCIVLSGGNVDLT-SLNWVGQAERPAPYQTVSV 339 SRR_HUMAN FQTVSPEVKNICIVLSGGNVDLTSSITWVKQAERPASYQSVSV 340 SRR_SCHPO E---KLKNKRIGIIISGGNVDIERYAHFLSQ--------- 323 $\star: *:: \star \star \star \star \star *: \quad: *$

FIGURE 3 | Sequence alignment (Clustal O) of SR from mouse, human and S. pombe. Color code: ATP binding site (lime); ATP hydrogen bonding network (cyan highlight or outline); $\pi$-stacking residue (magenta) and catalytic residues (yellow); "triple serine loop" region by analogy with aspartate racemase (gray); tetraglycine loop (green); divalent cation binding site (navy blue); pyridine-N-protonating residue (violet). Red letters indicate positions that have been mutated. *conserved residue: strongly similar residues. Weakly similar residues.

The greater need for charge delocalization (and hence pyridine $\mathrm{N}$-protonation) for PLP-enzyme-mediated transamination, as opposed to $\beta$-elimination or racemization chemistry, is supported by the results of a seminal study employing deaza-PLP (Griswold and Toney, 2011). These workers compared all three of these classes of PLP enzymes with both the native cofactor and its synthetic deaza-analog. Upon removing the ring nitrogen, by far the biggest penalty paid in $\mathrm{k}_{\mathrm{cat}}$ is for transamination, with aspartate aminotransferase suffering an $\sim 10^{9}$-fold decrease in activity. On the other hand, the $\beta$-eliminase OASS experiences only a 260 -fold decrease and alanine racemase sees an $\sim 700$-fold decrease in $\mathrm{k}_{\text {cat }}$. Griswald and Toney conclude that upon breaking the $\mathrm{C} \alpha-\mathrm{H}$ bond, transaminases delocalize charge fully into the PLP ring, while $\beta$-eliminases and racemase enzymes operate via a "carbanionic intermediate" with a more localized azallylic charge distribution across $\mathrm{C} \alpha$ and C4'.

\section{Nature of the Electron Sink: Quinonoid vs. Carbanionic Intermediate}

The PLP-imine $\pi$-system is often described as a four-electron sink. The pyridine nitrogen is thought of as the primary locus for the first two electrons stored in the extended $\pi$-system, with the imine nitrogen then in position to accept a second pair of electrons as, for example, would be required for a $\gamma$-replacement enzyme. Prior to such elegant physical organic chemical tools that are now available to interrogate reaction mechanism, it was long assumed, following the pioneering stereoelectronic arguments of
Dunathan (Dunathan, 1966), that PLP enzymes catalyzing C $\alpha$ $\mathrm{H}, \mathrm{C} \alpha-\mathrm{C}$, or $\mathrm{C} \alpha-\mathrm{COOH}$ bond cleavage would fully delocalize the resultant electron density into the $\pi$-system of the PLP-imine, the most stable resonance form of which would place those electrons on the pyridine nitrogen (Walsh, 1979). The ability to form a charge-balanced, net-neutral quinonoid intermediate would then require the pyridine nitrogen to be protonated. While this is clearly possible when an Asp (or potentially Glu) residue is so positioned in the active site, full protonation of the PLP ring nitrogen with a Ser, Cys, or Arg residue, for example, would require that these residues have abnormally low $\mathrm{pK}_{\mathrm{a}}$ values in the given PLP enzyme active site.

Consistent with this reasoning, to our knowledge, quinonoid intermediates have only been observed for PLP enzyme active sites that do feature an acidic residue donating a proton to the PLP ring nitrogen. Because such quinonoid intermediates feature an extended quinone-like $\pi$-system, these species absorb well into the visible, typically with $\lambda_{\max } \sim 480-550 \mathrm{~nm}$. Quinonoid intermediates have been observed by stopped flow spectrophotometry in enzymes that natively feature aspartate residues protonating the pyridine nitrogen (Metzler et al., 1988; Phillips et al., 1998; Karsten et al., 2005). In enzymes in which this residue is natively a serine, such as tryptophan synthase (Jhee et al., 1998) or an arginine such as alanine racemase (Sun and Toney, 1999), mutation of these residues to Asp or Glu, respectively, allows for the observation of quinonoid intermediates that had otherwise been unobservable. 


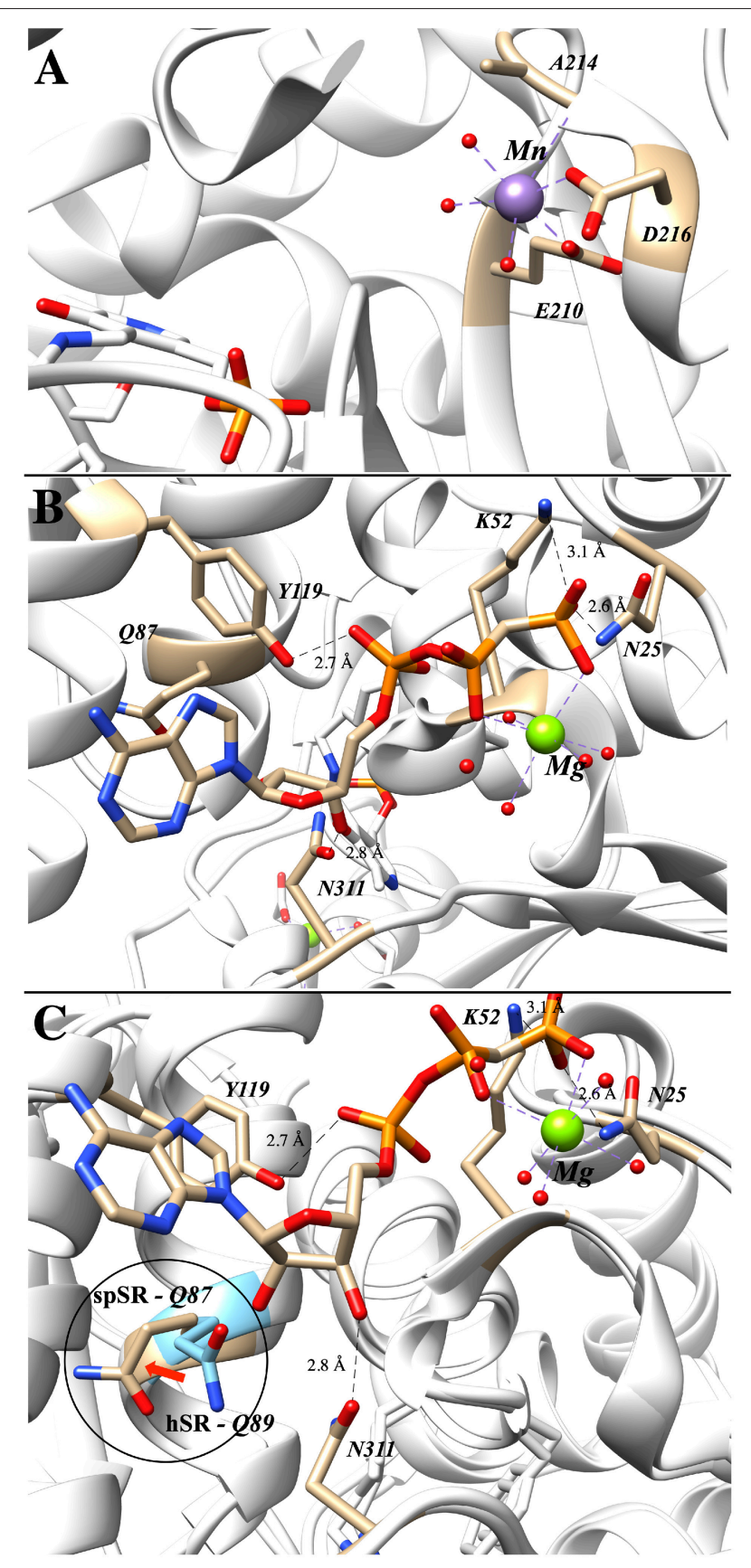

FIGURE 4 | (A) Mn²+ occupying the metal binding site in hSR; both E210 and D216 are within $2.1 \AA$ of the divalent metal (3L6B). (B) Binding of the second ATP-associated metal from the AMP-PCP-bound structure of S. pombe SR (1WTC). (C) Overlay of human (blue) and S. pombe (tan) SR highlighting the movement of Q89 upon ATP-binding (Q89 in hSR and Q87 in spSR).

These experiments suggest several alternative possibilities for catalysis with an enzyme such as tryptophan synthase. Catalysis might proceed (i) in a concerted fashion without buildup of negative charge in an intermediate or transition state, (ii) via a more localized carbanionic intermediate in which the charge is not delocalized significantly into the aromatic $\pi$-system of the PLP ring, or (iii) via a fully delocalized quinonoid intermediate with a lifetime that is too short to observe

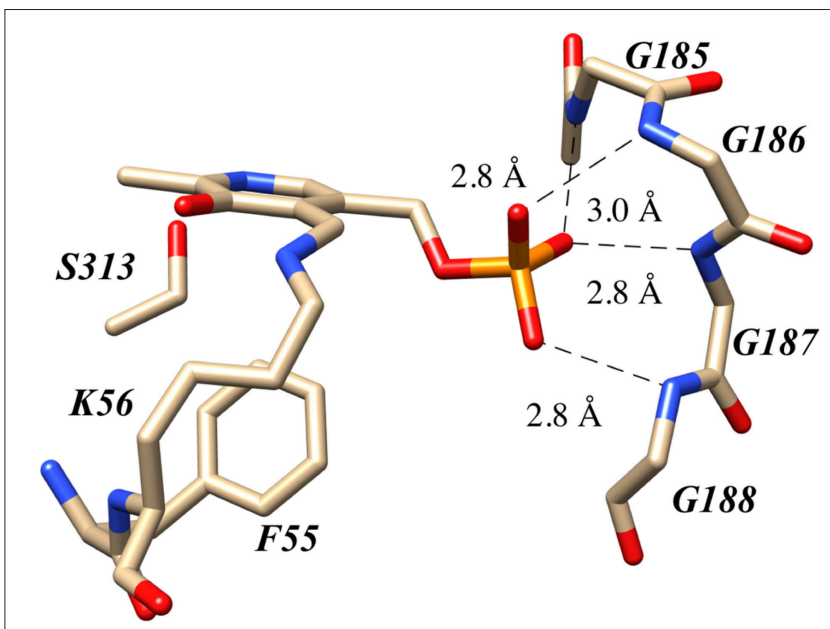

FIGURE 5 | The canonical tetraglycine loop that serves as a PLP phosphate binding pocket as seen in the hSR structure PDB code:3L6B.

with typical stopped flow instruments. In fact, collaborative work by Dunn and Mueller, utilizing a combination of NMR, $\mathrm{X}$-ray crystallography and computational modeling (Caulkins et al., 2016; Huang et al., 2016), provides evidence for the intermediate case just described; namely, for the formation of such a localized "carbanionic intermediate." As is shown in Figure 7A, this non-planar intermediate is thought to distribute electron density across the $\mathrm{C} \alpha-\mathrm{N}-\mathrm{C} 4$ '-azallylic system rather than into the pyridine $\pi$-system. The active site lysine $\varepsilon$-ammonium ion is seen in close enough proximity to electrostatically stabilize this "carbanionic intermediate."

A related observation was made for the enzyme drosophila cystathionine $\beta$-synthase (CBS), by Banerjee, Smith and coworkers via $\mathrm{X}$-ray crystallography (Figure 7B) (Koutmos et al., 2010). Here, too, a non-planar structure is seen for the putative "carbanionic intermediate" with L-serine substrate at $\mathrm{pH}$ 7. The azallylic C4'-N-C $\alpha$-anion is puckered upward toward the re-face, out of the plane of the pyridine ring system. Upon lowering the $\mathrm{pH}$ to $6.5, \beta$-elimination apparently occurs, and one sees the resultant aminoacrylate intermediate in the crystal. Consistent with these crystallographic results, stopped flow spectrophotometric analysis provides evidence for an aminoacrylate intermediate at $460 \mathrm{~nm}$. Another intermediate is also seen at $315 \mathrm{~nm}$, potentially the azallylic carbanionic species, as such a lower $\lambda_{\max }$ value would be expected for such a system with limited charge delocalization.

It should be noted that both cystathionine $\beta$-synthase and tryptophan synthase have similar active sites to that of serine racemase, as all three contain a serine hydroxyl in position to protonate the pyridine ring nitrogen. These studies thus suggest that the bifurcating racemase/ $\beta$-eliminase activity of SR may proceed by way of such an incompletely delocalized "carbanionic intermediate."

\section{ACTIVE SITE}

\section{Essential Lysine}

The essential lysine residue is found in all PLP-dependent enzymes, serving as a handle for the covalent attachment of 


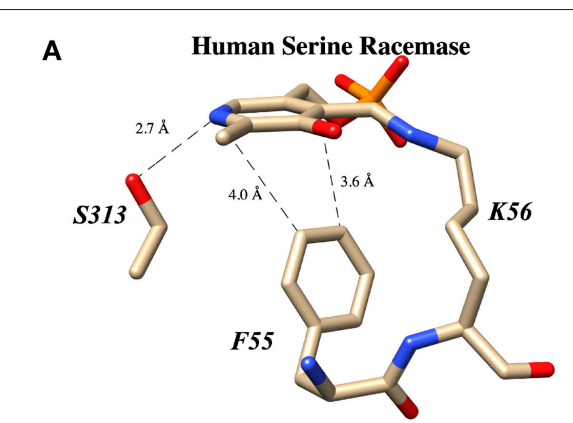

B

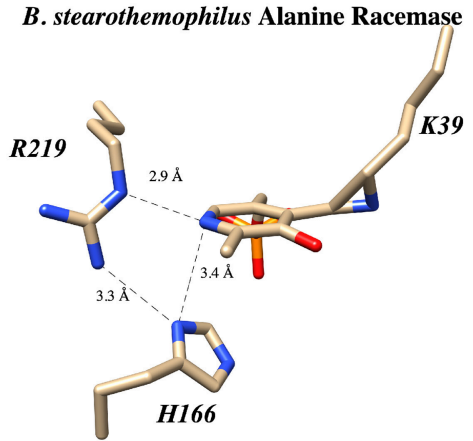

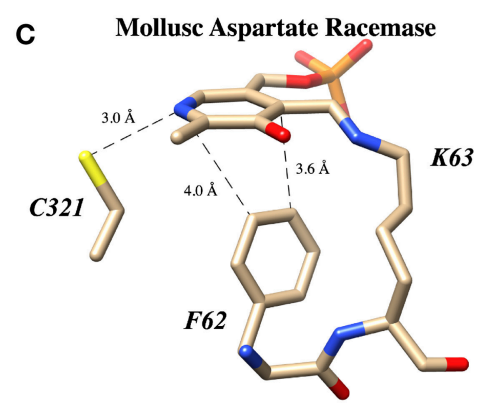

D Human Serine Dehydratase

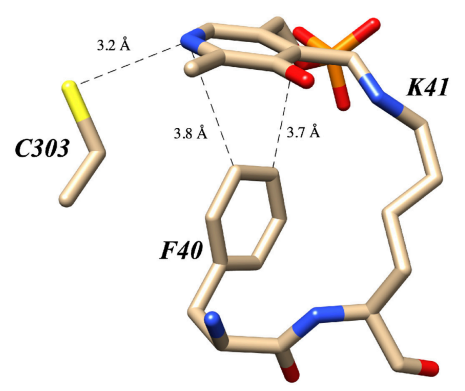

E
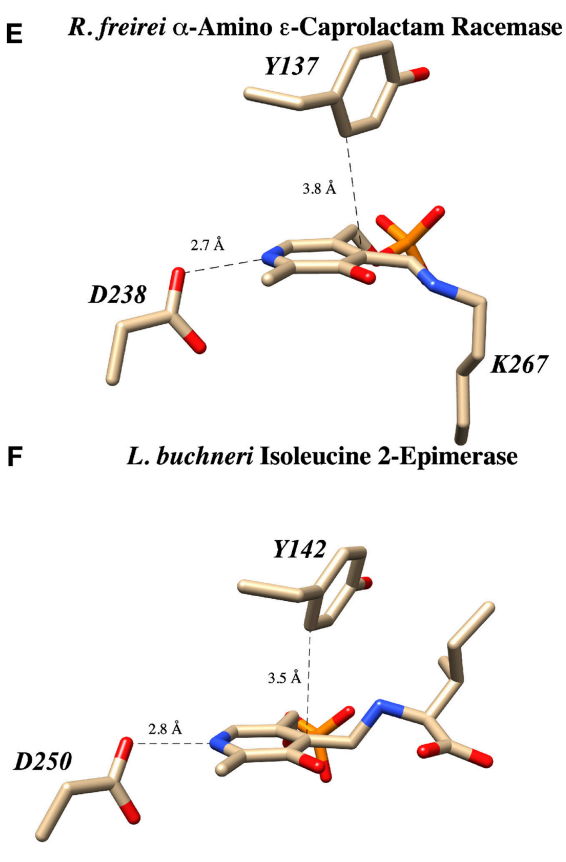

FIGURE 6 | PLP binding sites in known racemase structures illustrating hydrogen bonding and $\pi$-facial interactions of the pyridine ring. (A) hSR: pyridine $\mathrm{H}$-bonding with S313 and edge-to-face $\pi-\pi$ interaction with F55 (PDB code: 3L6B). (B) Alanine racemase: presumably weak pyridine H-bonding with R219 (PDB code: 1 SFT). (C) Aspartate racemase: pyridine $\mathrm{H}$-bonding with $\mathrm{C} 321$ and edge-to-face $\pi-\pi$ interaction with F62 (PDB code: 5YBW). (D) Human serine dehydratase: pyridine $\mathrm{H}$-bonding with $\mathrm{C} 303$ and edge-to-face $\pi-\pi$ interaction with F40 (PDB code: 4H27). (E) $\alpha$-Amino $\varepsilon$-caprolactam racemase: pyridine $\mathrm{H}$-bonding with D238 and edge-to-face $\pi-\pi$ interaction with Y137 (PDB code: 5M46). (F) Isoleucine 2-epimerase: pyridine H-bonding with D250 and edge-to-face $\pi-\pi$ interaction with Y142 PDB code: 5WYA.

the PLP cofactor in the internal aldimine. There are clear kinetic advantages of such an aldimine linkage, as this allows the amino acid substrate to rapidly form the external aldimine via a facile transaldimination reaction that passes through a gem-diamine intermediate. Essential lysine mutants generally lose orders of magnitude in catalytic efficiency but are still useful for the study of enzyme structure and mechanism. These mutants often retain the ability to non-covalently bind the PLP cofactor and support formation of the external aldimine by a much less efficient amine-aldehyde condensation rather than by the usual transaldimination mechanism. Perhaps, more importantly, such a mutation also means that the si-face base has been lost. For example, in possibly the most wellstudied PLP enzyme, aspartate aminotransferase, the K258A mutant exhibits a $10^{8}$-fold decrease in activity (Toney and Kirsch, 1993; Griswold and Toney, 2011) relative to the wild type. In CBS, the K119A mutant displays a $10^{3}$-fold decrease in activity. However, addition of the exogenous base ethylamine allows for a 2 -fold gain in activity, perhaps reflecting external compensation for this lost si-face base activity (Evande et al., 2004).

\section{Putative re-face Base}

In hSR, the essential lysine, Lys56, is thought to be the $s i$-face base responsible for $\alpha$-deprotonation of $\mathrm{L}$-serine or related substrates in human serine racemase. Ser84 has been proposed to be the complementary re-face base, responsible for reprotonation at the $\alpha$-carbon to form $\mathrm{D}$-serine. Crystallography demonstrates that this serine is highly conserved for hSR and its homologs in various other organisms (Goto et al., 2009; Koutmos et al., 2010). However, at physiological pH, the serine hydroxyl $\mathrm{pK}_{\mathrm{a}}$ is estimated to be too high to serve as a catalytically efficient general acid. Recently, based upon crystallographic considerations, Berkowitz and co-workers suggested a possible mechanism through which the effective $\mathrm{pK}_{\mathrm{a}}$ of Ser84 may be lowered in the hSR active site. Namely, these workers noted that the hSR structure features a potential Ser84-Wat372-Lys114 hydrogen bonding network (Nelson et al., 2017) resembling the Ser-cis-Ser-Lys catalytic triad of the amidase signature enzyme family (Ekici et al., 2008; Mileni et al., 2009; Pratt and McLeish, 2010; Lee et al., 2015; Cerqueira et al., 2017).

Several groups have expressed the re-face base Ser to Ala mutant in serine racemase enzymes from Dictyostelium discoideum (slime mold), S. pombe, and humans (Goto et al., 2009; Bodhinathan et al., 2010; Nelson et al., 2017). In all cases, as expected, racemization activity is lost. For the mammalian enzyme, $\beta$-elimination of L-serine to pyruvate persists but undergoes a 6 -fold reduction in catalytic efficiency $\left(\mathrm{k}_{\mathrm{cat}} / \mathrm{K}_{\mathrm{m}}\right)$, as can be seen in Table 1. The normal hSR preference for the negatively charged $\beta$-elimination substrates L-threo- $\beta$-hydroxyaspartate (L-THA) and L-serine-O-sulfate (L-SOS), also persists in the S84A mutant (Strísovský et al., 2005). 


\section{A Tryptophan Synthase}

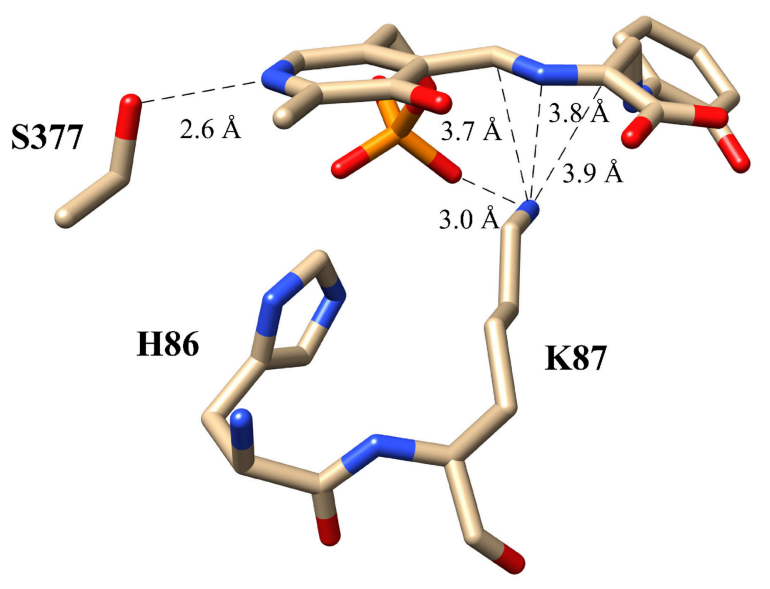

B Cystathionine $\beta$-Synthase

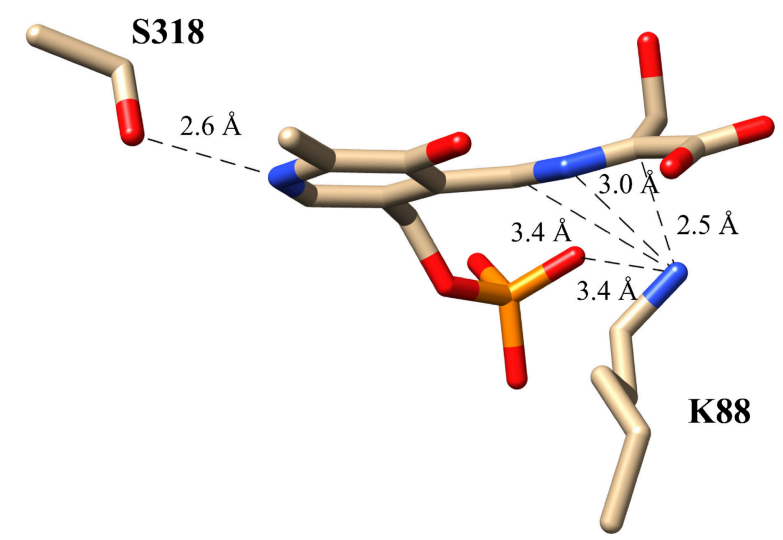

FIGURE 7 | Putative carbanionic intermediates as observed via x-ray crystallography. (A) Tryptophan synthase structure evidencing a "carbanonic intermediate" formed by addition of 2-aminophenol to the aminoacrylate intermediate (PDB code: 4HJP). This model is supported by Gaussian 09-based computations. (B) Cystathionine $\beta$-synthase structure featuring a similar "carbanionic intermediate" observed at $\mathrm{pH} 7$ and hypothesized to be electrostatically stabilized by K88 (PDB code: 3PC4).

\section{S84D Mutant Reveals Importance of R135 in Controlling $\beta$-Elimination Substrate Preferences}

When Ser84 is mutated to an acidic aspartate residue, the S84D mutant again loses the ability to catalyze the racemization reaction, as expected. The $\beta$-elimination chemistry of this mutant, however, demonstrates a surprising reversal of substrate preference. The native enzyme prefers the elimination substrates L-SOS and L-THA, each of which displays a negatively charged side chain over L-Ser $\sim 100: 1$. This ratio changes to 50:1 in favor of L-Ser in the S84D mutant. This corresponds to a $\sim 5,000$-fold swing in L-Ser to L-THA preference and a $\sim 1,200$-fold change in L-Ser to L-SOS processing efficiency. The S84D hSR mutant thus displays a an inverted $\beta$-elimination substrate bias toward L-Ser of 50:1 vs. L-THA and of 12:1 vs. L-SOS (Nelson et al., 2017).
TABLE 1 | Kinetics of hSR mutants highlighting the S84D mutants switch in preference to elimination of serine over charged substrates and the interesting preference of S84T for L-SOS over L-THA [table adapted with permission of the American Society for Biochemistry and Molecular Biology (ASBMB) (Nelson et al., 2017)].

\begin{tabular}{lccc}
\hline & \multicolumn{3}{c}{$\mathbf{k}_{\text {cat }} / \mathbf{K}_{\mathbf{m}}$ (Sub.): $\mathbf{k}_{\mathbf{c a t}} / \mathbf{K}_{\mathbf{m}}$ (L-Ser) } \\
\cline { 2 - 4 } Variant & L-SOS & L-THA & L-Ser vs. L-SOS vs. L-THA \\
\hline WT & $100: 1$ & $93: 1$ & $1: 100: 93$ \\
S84A & $71: 1$ & $34: 1$ & $1: 71: 34$ \\
S84D & $1: 12$ & $1: 50$ & $50: 4: 1$ \\
S84N & $2.5: 1$ & $7: 1$ & $1: 2.5: 7$ \\
S84T & $370: 1$ & $50: 1$ & $1: 370: 50$ \\
\hline
\end{tabular}

Utilizing molecular dynamics simulation and docking, the Berkowitz group put forth a model based upon the Dunathan hypothesis (Dunathan, 1966) that is consistent with this finding (Nelson et al., 2017). The model is based upon stereoelectronics and the notion that the $\mathrm{C} \alpha-\mathrm{H}$ bond to be broken must be aligned with the extended $\pi$-system of the PLP-imine (Dunathan, 1966). For the wild-type enzyme, negatively charged substrates are predicted to be oriented via a salt bridge with R135 resulting in the proper alignment for deprotonation (Figure 8A). This model is also consistent with the crystal structure of hSR bound to malonate (3L6B), in which the $\beta$-carboxylate of the inhibitor forms a salt bridge with R135 (Koutmos et al., 2010). Molecular dynamics simulations of the S84D mutant suggest that D84 moves to form a new salt bridge with R135, thereby preventing the positively charged arginine guanidinium group from interacting with the negatively charged side chains of LTHA and L-SOS. This results in a less-than-optimal positioning of these substrates in their respective enzyme-bound external aldimines, with the Dunathan angle (dihedral angle $=\mathrm{H}-\mathrm{C} \alpha$ $\left.\mathrm{N}-\mathrm{C} 4^{\prime}\right)$ distorted from the ideal $90-46^{\circ}$ and $33^{\circ}$ for L-THA and L-SOS, respectively (Figure 8B) (Nelson et al., 2017).

In light of the S84D results, the S84N hSR mutant was also studied. Intermediate results were observed, with only a modest preference for L-SOS (2.5:1) and L-THA (7:1) over L-Ser being observed. L-Serine racemization was not detected but the $\beta$ elimination was nearly at wild-type catalytic efficiency. Molecular modeling suggests that the intermediate activity seen with LTHA may be due to two different conformations of the hSRbound external aldimine; in one, the R135 guanidinium group is engaged with the $\beta$-carboxylate of the substrate (better Dunathan alignment $\sim 82^{\circ}$ ), and in the other, R135 forms a salt bridge with the $\alpha$-carboxylate (Nelson et al., 2017).

Finally, the S84T mutant was also studied. This is the only hSR mutant studied that retains L-Ser racemization activity, albeit with a 10 -fold loss in efficiency. The $\beta$-elimination reaction of L-Ser is also less efficient by $\sim 1$ order of magnitude. As for the $\beta$-elimination reaction of the negatively charged substrates, this mutant shows a marked preference for L-SOS elimination (370:1 vs. L-Ser) over L-THA (50:1 vs. L-Ser) elimination. This L-SOS preference may be due to the fact that this substrate features a favorable $\beta$-sulfate leaving group that need not be protonated to leave, as compared with L-THA, for which the 
$\beta$-OH leaving group would require protonation to leave. It may simply be that in the S84T mutant, the general acid required for $\beta$-OH protonation in L-THA is not optimally positioned to do so (Nelson et al., 2017).

\section{Lys-N ${ }^{\varepsilon}$-Ala57 Extender Arm Variant}

An interesting apparent self-catalyzed active site modification reaction has been reported for the serine racemase from Schizosaccharomyces pombe (SpSR) by Esaki and Hirotsu and co-workers (Goto et al., 2009; Yamauchi et al., 2009). In one of the first three crystal structures published by this group for the $S$. pombe SR, it was observed that the essential lysine had been modified to a L-lysino-D-alanyl-residue upon extended incubation with L-serine. This amounts to a three-atom extension of the active site Lys-57 residue. The authors provide

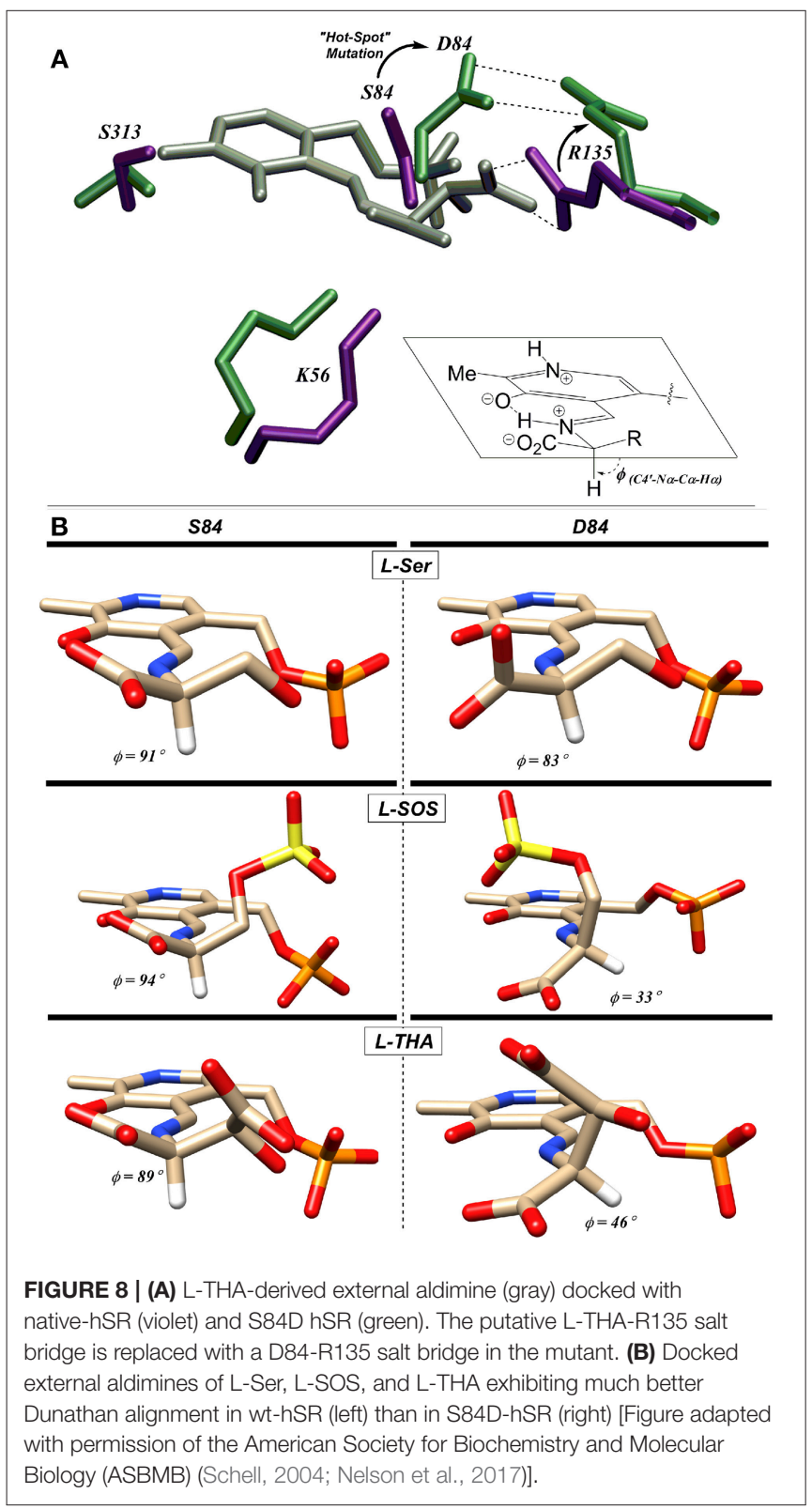

both mass spectrometric $(+87)$ and $\mathrm{x}$-ray crystallographic evidence in support of this structure. They claim that a $97 \%$ level of modification is seen.

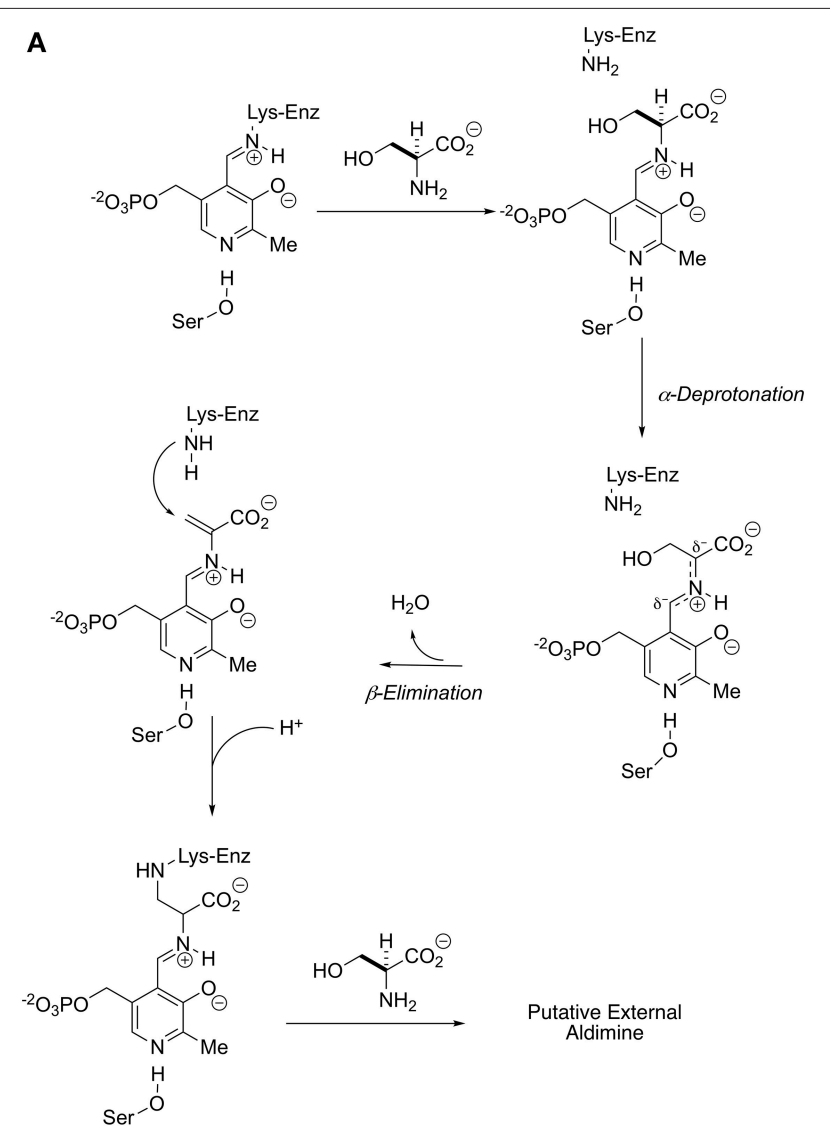

B

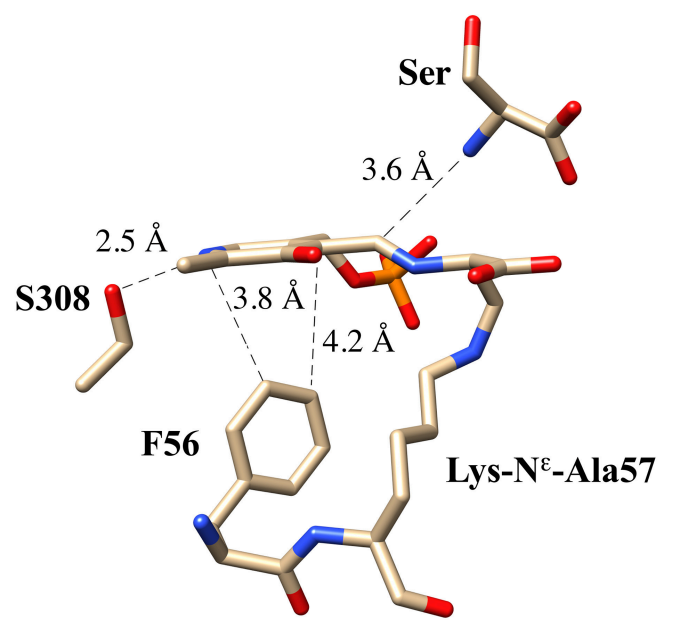

FIGURE 9 | Extender arm of the essential lysine observed by crystallography of $S$. pombe serine racemase. (A) Potential mechanism for formation of the extender arm. (B) Crystal structure of the internal aldimine with the "extended"-lysine residue (2ZR8). 
Even though this modification places a carboxylate group alpha- to this active site "extended" lysine residue, the modified SpSR maintains $54 \%$ of the racemization activity and $68 \%$ of the $\beta$-elimination activity of the wt-enzyme. This self-catalyzed modification of the essential lysine of SpSR is proposed to occur by elimination of water from serine and the conjugate addition of the essential lysine into the resultant PLP-bound aminoacrylate intermediate (Figure 9A). In addition to revealing the three-dimensional structure of this modified enzyme, the crystal structure also appears to show a near attack conformation of an L-serine molecule approaching the lysino-D-alanyl-internal aldimine as would be expected for a transaldimination reaction of this modified enzyme (Figure 9B) (Goto et al., 2009). It remains to be seen if similar behavior will be observable in mammalian SR enzymes.

\section{Residues Influencing Racemization vs. $\beta$-Elimination - "Triple Serine Loop"}

As is illustrated schematically in Figure 2, one observes a bifurcating L-Ser racemization (giving D-Ser product) vs. LSer $\beta$-elimination (giving pyruvate product) mechanism for the enzyme serine racemase. This raises several important questions.
(1) Is this observed bifurcating activity biologically relevant, incidental, or even an artefact of the assay conditions in vitro? (2) If the bifurcation is biologically relevant, what are the key biological determinants of whether hSR drives L-Ser substrate more toward D-Ser or pyruvate? (3) What are the key structural/mechanistic features along the reaction coordinate that control the "decision" to racemize or $\beta$-eliminate substrate?

As to the relevance of the in vitro assay, it is necessary to note here that hSR is known to be engaged in protein-protein interactions in vivo that may influence catalytic activity and/or bifurcation ratio. These include reported interactions with PICK 1 (protein interacting with C-kinase) (Hikida et al., 2008), GRIP (glutamate receptor interacting protein) (Baumgart et al., 2007), stargazin and PSD95 (postsynaptic D protein 95) (Ma et al., 2014) and DISC 1 (disrupted in schizophrenia) (Ma et al., 2013; Xia et al., 2016). That said, for now, in the absence of compelling evidence that the overall kinetic profile is significantly altered by such PPIs, we will proceed to analyze hSR performance by steadystate kinetic analysis in isolated enzyme assays, with both divalent cation and ATP present.

As we and others have noted (Strísovský et al., 2003; Nelson et al., 2017), under such conditions, wt-hSR favors the L-Ser

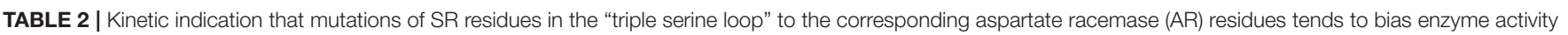
toward racemization over $\beta$-elimination.

\begin{tabular}{|c|c|c|c|c|c|c|c|c|}
\hline \multirow[t]{2}{*}{ Variant } & \multicolumn{4}{|c|}{ Position } & \multirow{2}{*}{$\begin{array}{l}\text { Racemization } \\
\text { Efficiency }{ }^{\ddagger}\end{array}$} & \multirow{2}{*}{$\begin{array}{c}\mathbf{k}_{\text {cat }}(\text { rac }): \\
\mathbf{k}_{\text {cat }}(\beta-\text {-elim })\end{array}$} & \multirow{2}{*}{$\begin{array}{c}\mathrm{K}_{\mathrm{cat}} / \mathrm{K}_{\mathrm{m}}(\mathrm{rac}): \\
\mathrm{K}_{\mathrm{cat}} / \mathrm{K}_{\mathrm{m}}(\beta-\mathrm{elim})\end{array}$} & \multirow[t]{2}{*}{ References } \\
\hline & 152 & 153 & 154 & 155 & & & & \\
\hline \multicolumn{9}{|c|}{ "Triple Ser Loop"- Relation to Racemase Activity } \\
\hline $\mathrm{hSR}^{+}$ & $\mathrm{H}$ & $\mathrm{P}$ & $\mathrm{N}$ & Q & 100 & $1: 4$ & $1: 3.7$ & $\begin{array}{l}\text { Hoffman et al., 2009; } \\
\text { Nelson et al., 2017; } \\
\text { Canosa et al., } 2018\end{array}$ \\
\hline $\mathrm{mSR}^{+}$ & $\mathrm{H}$ & $\mathrm{P}$ & $\mathrm{N}$ & Q & 133 & $1: 2.3$ & $1: 1.3$ & Uda et al., 2016 \\
\hline mSR & S & $P$ & $\mathrm{~N}$ & Q & - & - & $1: 1.4$ & Foltyn et al., 2005 \\
\hline $\mathrm{mSR}$ & S & $P$ & $\mathrm{~N}$ & Q & 121 & rac only* & rac only* & Uda et al., 2017 \\
\hline mSR & $\mathrm{H}$ & S & $\mathrm{N}$ & Q & - & - & $4: 1$ & Foltyn et al., 2005 \\
\hline $\mathrm{mSR}$ & $\mathrm{H}$ & S & $\mathrm{N}$ & Q & 1140 & 23:1 & $2: 1$ & Uda et al., 2017 \\
\hline $\mathrm{mSR}$ & $\mathrm{H}$ & $P$ & S & Q & 174 & $6.8: 1$ & 2.3:1 & Uda et al., 2017 \\
\hline mSR & $\mathrm{H}$ & $P$ & $\mathrm{~N}$ & $\mathrm{D}$ & $46(700)^{\ddagger}$ & $7: 1$ & 7.3:1 & Foltyn et al., 2005 \\
\hline $\mathrm{mSR}$ & S & S & $N$ & Q & 100 & rac only* & rac only* & Uda et al., 2017 \\
\hline $\mathrm{mSR}$ & $\mathrm{H}$ & S & S & Q & 376 & 3.5:1 & $1: 12.8$ & Uda et al., 2017 \\
\hline $\mathrm{mSR}$ & $S$ & $\mathrm{P}$ & $S$ & Q & 160 & rac only* & rac only ${ }^{*}$ & Uda et al., 2017 \\
\hline mSR & S & S & S & Q & 55 & rac only* & rac only* & Uda et al., 2017 \\
\hline $\mathrm{spSR}^{+}$ & $P$ & $P$ & Y & $\mathrm{D}$ & $\star \star$ & $1: 29^{\mathbb{I}}$ & $1: 26^{\S}$ & Yamauchi et al., 2009 \\
\hline $\operatorname{amAR}^{+}$ & $\mathrm{H}$ & $S$ & S & $\mathrm{D}$ & 24 & $8.6: 1$ & $2.2: 1$ & Uda et al., 2017 \\
\hline $\operatorname{cgAR}{ }^{+}$ & S & S & S & $\mathrm{D}$ & 18 & rac only* & rac only* & Uda et al., 2017 \\
\hline
\end{tabular}

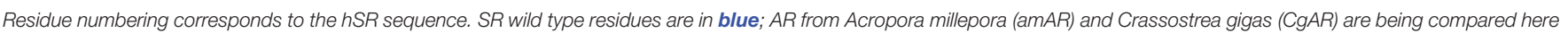
with the CgAR wild type residues appearing in green. Emboldened entries indicate enzymes for which racemization is preferred over elimination.

+ designates the wild type enzyme.

†These values are normalized to the average value of $k_{\text {cat }}$ for racemization for wt $h S R\left(30 \pm 15\right.$ min $\left.^{-1}\right)$ which is arbitrarily set at 100 .

*no $\beta$-elimination activity observed.

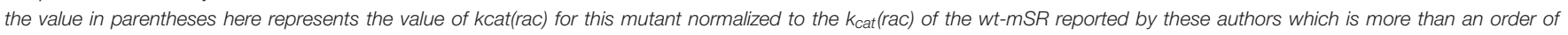
magnitude lower than that determined by other groups.

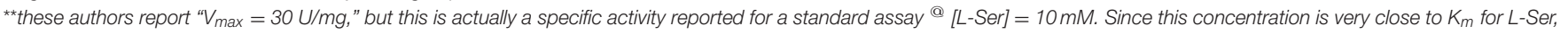
the velocities reported are well-below $V_{\text {max }}$.

It this value represents relative velocity for racemization vs. elimination at $10 \mathrm{mM}$ concentration rather than a ratio of $k c a t$ values.

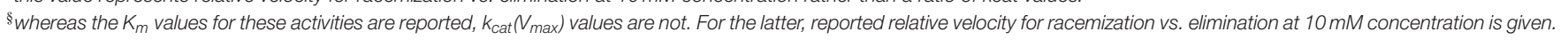


$\beta$-elimination reaction over the racemization reaction by a 4 $5: 1$ ratio. It may be that the $\beta$-elimination reaction serves as a sort of "bleed valve," potentially allowing local stores of LSer to be diverted to pyruvate and away from D-Ser as a mechanism for muting D-Ser signaling. This could be a sort of secondary checkpoint, providing a mechanism for managing steady-state L-Ser levels in the neuron, beyond the control that is exercised by the rate at which L-Ser is produced from 3phosphoglycerate in the astroglia and shuttled to the neuron (Figure 1) (Ishiwata et al., 2015; Wolosker et al., 2016). There has been a related discussion on hSR-mediated D-Ser $\beta$-elimination being a mechanism for controlling $\mathrm{D}$-Ser concentrations in the neuron (Foltyn et al., 2005; Wolosker, 2011).

As is illustrated in Figure 2, probably the most streamlined mechanism for this bifurcation would involve initial external aldimine formation of L-Ser, followed by $s i$-face deprotonation by K56 to a common "carbanionic" or quinonoid intermediate. As has been discussed earlier, elegant model studies by the Toney group (Griswold and Toney, 2011) suggest that neither racemase nor eliminase activity requires a completely delocalized quinonoid intermediate. These observations are consistent with the observation of "carbanionic intermediates" for the $\beta$ eliminase/replacement enzymes, CBS (Koutmos et al., 2010) and tryptophan synthase (Caulkins et al., 2016), as noted in Figure 7. As is shown in Figure 2, a likely decision point for bifurcation would then occur at the protonation step, with re-face protonation, presumably by Ser84, leading to racemization and with $\mathrm{OH}$-leaving group (LG) protonation leading to $\beta$-elimination.

Both the groups of Toney (Foltyn et al., 2005) and of Uda et al. $(2016,2017)$ have reported studies demonstrating that mutation of targeted residues can profoundly influence the racemization to $\beta$-elimination ratio in hSR and homologs. These results are summarized in detail in Table 2. Uda et al. performed a detailed phylogenetic analysis of the serine/aspartate racemase family and deduced that a so-called "triple serine loop" (Figure 10; named after the wt-AR sequence) may be critical for racemization function as residues here appear to correlate with a likely evolution from SR to AR activity.

Specifically, L-THA dehydratases and SRs from lower order organisms possess a loop region from amino acids P150, P151, and Y152. Tracing this loop region up the phylogenetic tree demonstrates that these residues change to H152, P153, and N154 in human and mouse SR. On the other hand, in aspartate racemases, these residues morph into a "triple serine loop" of sequence S150, S151, S152 as for example in the AR from Crassostrea gigas (CgAR) (Uda et al., 2016). For CgAR, this SSS motif appears to dictate the substrate preference for L-Asp over L-Ser. Wild-type S. pombe SR with the PPY sequence exhibits no AR activity, and mouse SR with the MPN sequence shows limited AR activity with $\mathrm{k}_{\mathrm{cat}} / \mathrm{K}_{\mathrm{m}} \sim 65 \mathrm{mM}^{-1} \mathrm{~min}^{-1}$ (Bodhinathan et al., 2010; Uda et al., 2016).

A secondary finding from these studies is that, in general, introducing residues representing the AR sequence into this loop in hSR tends to favor L-Ser racemization, by a combination of suppressing L-Ser $\beta$-elimination (or dehydrase activity) and promoting L-Ser racemization. Uda and co-workers cloned nearly a dozen SR and aspartate racemase enzymes and studied both the wt- and mutant versions of these enzymes kinetically. Earlier, the Toney group had also looked at SR mutants in this loop. From Table 2, it can be seen that installation of $S$ residues at positions 153 and 154 in hSR in particular tends to increase the $\mathrm{k}_{\mathrm{cat}}$ for racemization. Introduction of $\mathrm{S}$ into position 152 in mSR significantly decreases L-Ser $\beta$-elimination activity; a similar effect appears to result from introduction of a $D$ residue into position 155.

Most importantly, these studies demonstrate that for hSR, the bifurcation ratio is controlled significantly at the level of the primary sequence, with particular sensitivity to modifications in this "triple serine loop." Figure 10 illustrates that this loop is located just above the PLP-imine functionality in the external aldimine crystal structures for both the SR and AR enzymes. To understand the molecular basis for how specific mutants morph hSR activity from the native predilection for $\beta$-elimination to a preference for racemization, the tools of structural biology could be of great value.

\section{DISCUSSION AND CONCLUDING REMARKS}

From an evolutionary standpoint, it appears that serine racemase activity may have evolved from L-threo-hydroxyaspartate (LTHA) eliminase activity and may also have served as the

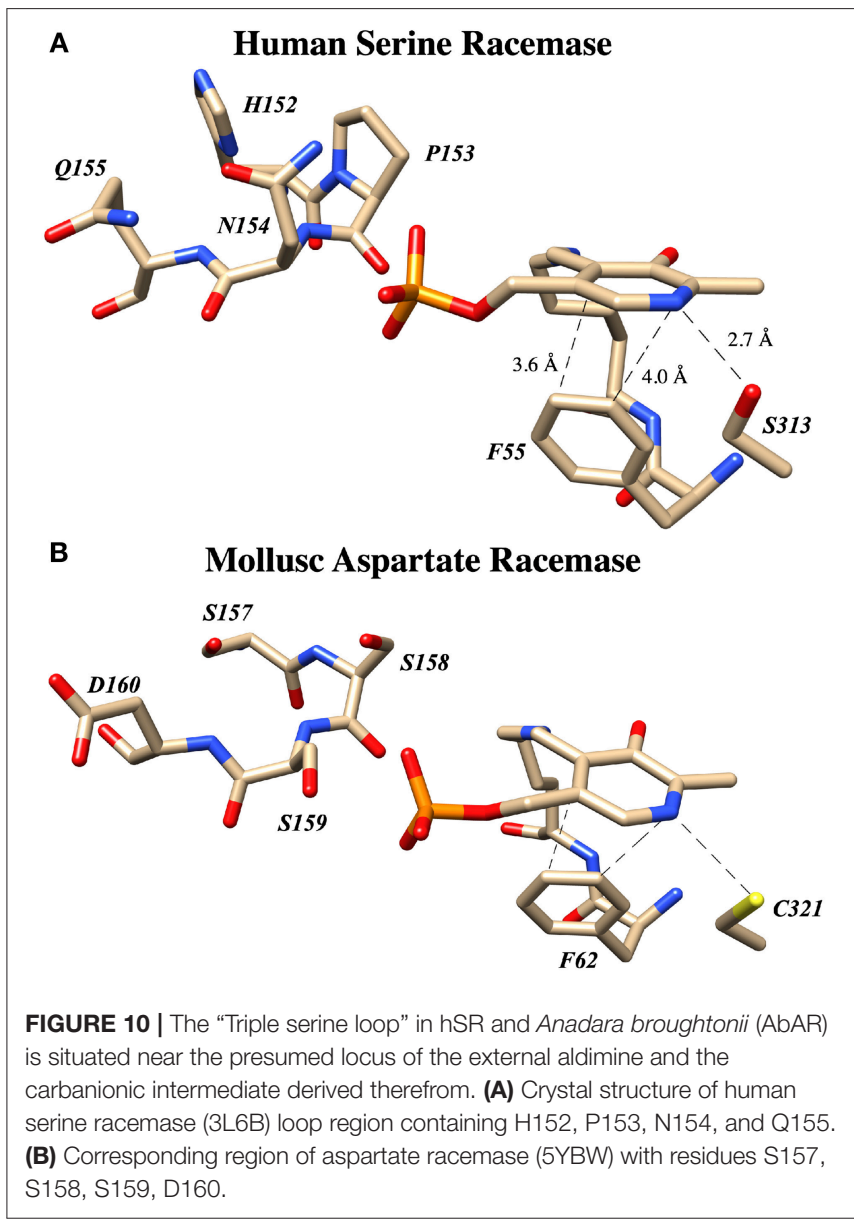


evolutionary precursor to aspartate racemase (AR). Consistent with this view, both the re-face base S84 and R135 in the human isoform are highly conserved across the SR family, and these residues are also conserved among enzymes demonstrating LTHA dehydratase activity (Nelson et al., 2017). Additionally, modifications in the loop region corresponding to positions 152-155 in hSR, from HPNQ to SSSD, appear to have been primary determinants in the evolution of AR function from SR function. Interestingly, a smaller subset of modifications here, specifically the P153S and N154S mutations, seem to confer a much greater L-Ser racemization bias into hSR, over competing L-Ser $\beta$-elimination activity, than is seen in the native enzyme. This observation suggests that there may be an advantage to maintaining $\beta$-eliminase activity in the native enzyme, perhaps as an additional control point for L-Ser homeostasis.

As has been discussed herein, the core of the hSR enzyme features an archetypical PLP binding site; this includes the active site lysine (K56) covalently engaging the cofactor, the tetraglycine loop binding the phosphate moiety (Figure 5), and both an $\mathrm{H}$ bond donor (S313) in the ring plane engaging the pyridine nitrogen and an edge-to-face $\pi-\pi$ interacting partner residue (F55) orthogonal to the ring plane (Figure 6). In the case of the SpSR enzyme, at least, that core can apparently be modified via an unusual $\beta$-elimination-K56/conjugate addition sequence, leading to an apparent lysino-D-alanyl extender arm version of the active site (Figure 9). Surrounding this PLP binding pocket are key catalytic residues, including $\mathrm{K} 56$, which doubles as the si-face base; S84, which serves as the re-face base for the racemization; and R135, which appears to help position negatively charged substrates, such L-SOS and L-THA, for elimination (Figure 8), and which can be exploited for inhibitor binding, as is seen in the binding motif for malonate. The acidity of S84 may be modulated by K114 via an H-bonding network through a bound water molecule (Nelson et al., 2017).

Activity of the hSR enzyme is stimulated by both divalent cations and ATP, with the latter likely operating via an allosteric mechanism associated with a conformational change upon nucleotide binding that depends upon interactions with Q89 (Figure 4). Catalytic activity of the enzyme follows a bifurcated pathway from L-Ser to either D-Ser (racemization) or pyruvate ( $\beta$-elimination), likely through a common "carbanionic intermediate," the molecular nature and charge distribution of which is yet to be established (Figure 2). Whereas, wt-hSR favors the $\beta$-elimination reaction over the racemization reaction, this preference can be inverted through specific mutations in the hSR152-155 loop region ("triple serine loop" in AR;

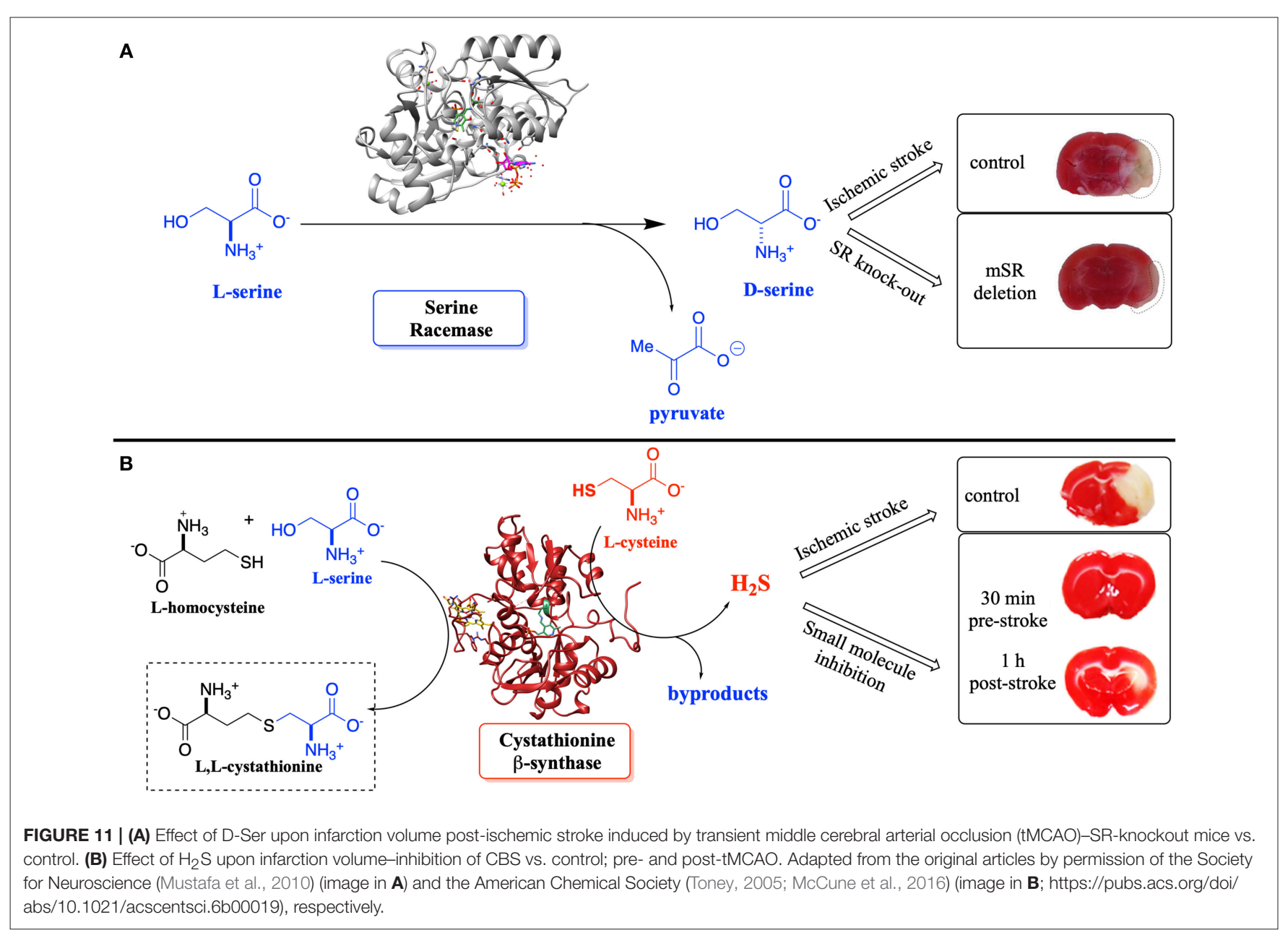


Table 2 and Figure 10). Elucidation of the molecular basis of this reaction pathway tuning will likely require more precise structural biological studies of appropriate (mutant) enzymesubstrate combinations in the future.

Such detailed studies of hSR structure/function relationships are critical given the importance of the enzyme in neuronal signaling via the NMDAR, in neuronal infarction pathways, and potentially in the etiology of neurodegenerative disease. Note that D-Ser and $\mathrm{H}_{2} \mathrm{~S}$, a product of CBS, another PLP-enzyme that controls neuronal signaling, are thought to stimulate the NMDAR (Figure 1) (Kimura, 2000, 2015; Kimura et al., 2013). Both $\mathrm{D}$-Ser and $\mathrm{H}_{2} \mathrm{~S}$ are thought to be elevated pursuant to ischemic stroke, and model studies in a tMCAO (transient middle cerebral arterial occlusion) rat stroke model suggest that both hSR (Mustafa et al., 2010) and hCBS (McCune et al., 2016) may be potential targets for inhibition to mitigate against neuronal infarction in ischemic stroke (Figure 11).

In a recent cell biology-based study on apoptosis, HEK $293 \mathrm{~T}$ cells expressing the Q155D-hSR mutant (favoring L-Ser-to-DSer racemization over $\beta$-elimination) demonstrated a reduced rate of cell death when apoptotic agent staurosporine was introduced, indicating that the racemization reaction (i.e., DSer) may have a protective role against apoptosis (Talukdar et al., 2017). While these results are compelling, they also call out as a challenge to chemists the need to develop selective small molecule modulators of hSR that either inhibit or stimulate the enzyme or that modulate the inherent $\beta$-eliminase to racemase preference of the enzyme. This serves as motivation in our own laboratory to develop reaction-specific PLP enzyme inhibitors based upon mechanistic understanding (Berkowitz et al., 1994, 1996, 2004, 2008; Berkowitz and Smith, 1996; Karukurichi et al., 2007; McCune et al., 2016, 2017; Tu et al., 2018). If such hSR

\section{REFERENCES}

Azam, M. A., and Jayaram, U. (2016). Inhibitors of alanine racemase enzyme: a review. J. Enz. Inhib. Med. Chem. 31, 517-526. doi: 10.3109/14756366.2015.1050010

Baumgart, F., Mancheño, J. M., and Rodríguez-Crespo, I. (2007). Insights into the activation of brain serine racemase by the multi-PDZ domain glutamate receptor interacting protein, divalent cations and ATP. FEBS J. 274, 4561-4571. doi: 10.1111/j.1742-4658.2007.05986.x

Berger, A. J., Dieudonné, S., and Ascher, P. (1998). Glycine uptake governs glycine site occupancy at NMDA receptors of excitatory synapses. J. Neurophys. 80, 3336-3340. doi: 10.1152/jn.1998.80.6.3336

Berkowitz, D. B., de la Salud-Bea, R., and Jahng, W.-J. (2004). Synthesis of quaternary amino acids bearing a $\left(2^{\prime} \mathrm{Z}\right)$-fluorovinyl $\alpha$-Branch: potential PLP enzyme inactivators. Org. Lett. 6, 1821-1824. doi: 10.1021/ol049422u

Berkowitz, D. B., Jahng, W. J., and Pedersen, M. L. (1996). $\alpha$-Vinyllysine and $\alpha$-vinylarginine are time-dependent inhibitors of their cognate decarboxylases. Bioorg. Med. Chem. Lett. 6, 2151-2156. doi: 10.1016/0960-894X(96) 00366-6

Berkowitz, D. B., Karukurichi, K. R., de la Salud-Bea, R., Nelson, D. L., and McCune, C. D. (2008). Use of fluorinated functionality in enzyme inhibitor development: mechanistic and analytical advantages. J. Fluorine Chem. 129, 731-742. doi: 10.1016/j.jfluchem.2008.05.016

Berkowitz, D. B., Pumphrey, J. A., and Shen, Q. (1994). Enantiomerically enriched $\alpha$-vinyl amino acids via lipase mediated "reverse transesterification". Tetrahedron Lett. 35, 8743-8746. doi: 10.1016/S0040-4039(00)78486-3 inhibitors/modulators can be developed, they will serve as tools for chemical biology, and potentially as leads for medicinal chemistry in the effort to understand hSR function in the context of neuronal signaling and D-serine neurobiology.

\section{DEDICATION}

We wish to dedicate this article to Christopher T. Walsh on the 40th anniversary of his seminal treatise on enzymatic reaction mechanisms.

\section{DATA AVAILABILITY}

Publicly available datasets were analyzed in this study. This data can be found here: https://www.rcsb.org/pdb/home/sitemap.do.

\section{AUTHOR CONTRIBUTIONS}

All authors listed have made a substantial, direct and intellectual contribution to the work, and approved it for publication.

\section{FUNDING}

The studies described in the Berkowitz group were supported by the American Heart Association (Grant-InAid- 16GRNT313400012) and the National Science Foundation (CHE-1500076 and CHE-1800574). This research was facilitated by the IR/D (Individual Research and Development) program associated with DBB's appointment at the National Science Foundation. The authors thank the NIH (SIG-1-510-RR06307) and NSF (CHE-0091975, MRI-0079750) for NMR instrumentation support and the NIH (RR016544) for research facilities.

Berkowitz, D. B., and Smith, M. K. (1996). A convenient synthesis of L- $\alpha$-vinylglycine from L-homoserine lactone. Synthesis 1, 39-41. doi: 10.1055/s-1996-4177

Bodhinathan, K., Kumar, A., and Foster, T. C. (2010). Intracellular redox state alters NMDA receptor response during aging through $\mathrm{Ca}^{2+} /$ calmodulin-dependent protein kinase II. J. Neurosci. 30, 1914-1924. doi: 10.1523/JNEUROSCI.5485-09.2010

Campanini, B., Spyrakis, F., Peracchir, A., and Mozzarelli, A. (2013). Serine racemase: a key player in neuron activity and in neuropathologies. Front. Biosci. 18, 1112-1128. doi: 10.2741/4167

Canosa, A. V., Faggiano, S., Marchetti, M., Armao, S., Bettati, S., Bruno, S., et al. (2018). Glutamine 89 is a key residue in the allosteric modulation of human serine racemase activity by ATP. Sci. Rep. 8:9016. doi: 10.1038/s41598-018-27227-1

Caulkins, B. G., Young, R. P., Kudla, R. A., Yang, C., Bittbauer, T. J., Bastin, B., et al. (2016). NMR crystallography of a carbanionic intermediate in tryptophan synthase: chemical structure, tautomerization, and reaction specificity. J. Am. Chem. Soc. 138, 15214-15226. doi: 10.1021/jacs.6b08937

Cerqueira, N. M. F. S. A., Moorthy, H., Fernandes, P. A., and Ramos, M. J. (2017). The mechanism of the Ser-(cis)Ser-Lys catalytic triad of peptide amidases. Phys. Chem. Chem. Phys. 19, 12343-12354. doi: 10.1039/C7CP00277G

Chan-Huot, M., Dos, A., Zander, R., Sharif, S., Tolstoy, P. M., Compton, S., et al. (2013). NMR studies of protonation and hydrogen bond states of internal aldimines of pyridoxal 5'-phosphate acid-base in alanine racemase, aspartate aminotransferase, and poly-L-lysine. J. Am. Chem. Soc. 135, 18160-18175. doi: $10.1021 /$ ja408988z 
Cook, S. P., Galve-Roperh, I., Del Pozo, A. M., and Rodríguez-Crespo, I. (2002). Direct calcium binding results in activation of brain serine racemase. J. Biol. Chem. 277, 27782-27792. doi: 10.1074/jbc.M111814200

Coyle, J. T., and Balu, D. T. (2018). The role of serine racemase in the pathophysiology of brain disorders. Adv. Pharmacol. 82, 35-56. doi: 10.1016/bs.apha.2017.10.002

De Miranda, J., Panizzutti, R., Foltyn, V. N., and Wolosker, H. (2002). Cofactors of serine racemase that physiologically stimulate the synthesis of the N-methylD-aspartate (NMDA) receptor coagonist D-serine. Proc. Natl. Acad. Sci. U S A. 99, 14542-14547. doi: 10.1073/pnas.222421299

De Miranda, J., Santoro, A., Engelender, S., and Wolosker, H. (2000). Human serine racemase: molecular cloning, genomic organization and functional analysis. Gene 256, 183-188. doi: 10.1016/S0378-1119(00)00356-5

Du, S., Wang, Y., Weatherly, C. A., Holden, K., and Armstrong, D. W. (2018). Variations of L- and D-amino acid levels in the brain of wild-type and mutant mice lacking D-amino acid oxidase activity. Anal. Bioanal. Chem. 410, 2971-2979. doi: 10.1007/s00216-018-0979-9

Dunathan, H. C. (1966). Conformation and reaction specificity in pyridoxal phosphate enzymes. Proc. Natl. Acad. Sci. U.S.A. 55, 712-716. doi: $10.1073 /$ pnas.55.4.712

Ekici, O. D., Paetzel, M., and Dalbey, R. E. (2008). Unconventional serine proteases: variations on the catalytic Ser/His/Asp triad configuration. Prot. Sci. 17, 2023-2037. doi: 10.1110/ps.035436.108

Evande, R., Ojha, S., and Banerjee, R. (2004). Visualization of PLP-bound intermediates in hemeless variants of human cystathionine $\beta$-synthase: evidence that lysine 119 is a general base. Arch. Biochem. Biophys. 427, 188-196. doi: 10.1016/j.abb.2004.04.027

Fesko, K., Suplatov, D., and Svedas, V. (2018). Bioinformatic analysis of the fold type I PLP-dependent enzymes reveals determinants of reaction specificity in L-threonine aldolase from Aeromonas jandaei. FEBS Open Bio. 8, 1013-1028. doi: 10.1002/2211-5463.12441

Foltyn, V. N., Bendikov, I., De Miranda, J., Panizzutti, R., Dumin, E., Shleper, M., et al. (2005). Serine racemase modulates intracellular D-serine levels through an $\alpha, \beta$-elimination activity. J. Biol. Chem. 280, 1754-1763. doi: $10.1074 /$ jbc.M405726200

Frese, A., Sutton, P. W., Turkenburg, J. P., and Grogan, G. (2017). Snapshots of the catalytic cycle of the industrial enzyme alpha-amino-epsilon-caprolactam racemase (ACLR) observed using x-ray crystallography. ACS Catal. 7, 1045-1048. doi: 10.1021/acscatal.6b03056

Fujii, K., Maeda, K., Hikida, T., Mustafa, A. K., Balkissoon, R., Xia, J., et al. (2006). Serine racemase binds to PICK1: potential relevance to schizophrenia. Mol. Psychiatry 11, 150-157. doi: 10.1038/sj.mp.4001776

Furukawa, H., and Gouaux, E. (2003). Mechanisms of activation, inhibition and specificity: crystal structures of the NMDA receptor NR1 ligand-binding core. EMBO J. 22, 2873-2885. doi: 10.1093/emboj/cdg303

Goto, M., Yamauchi, T., Kamiya, N., Miyahara, I., Yoshimura, T., Mihara, H., et al. (2009). Crystal structure of a homolog of mammalian serine racemase from Schizosaccharomyces pombe. J. Biol. Chem. 284, 25944-25952. doi: 10.1074/jbc.M109.010470

Griswold, W. R., and Toney, M. D. (2011). Role of the pyridine nitrogen in pyridoxal $5^{\prime}$-phosphate catalysis: activity of three classes of PLP enzymes reconstituted with deazapyridoxal $5^{\prime}$-phosphate. J. Am. Chem. Soc. 133, 14823-14830. doi: 10.1021/ja2061006

Hayashi, J., Mutaguchi, Y., Minemura, Y., Nakagawa, N., Yoneda, K., Ohmori, T., et al. (2017). Crystal structure of the novel amino-acid racemase isoleucine 2-epimerase from Lactobacillus buchneri. Acta Crystallogr. D Struct. Biol. 73, 428-437. doi: 10.1107/S2059798317005332

Hikida, T., Mustafa, A. K., Maeda, K., Fujii, K., Barrow, R. K., Saleh, M., et al. (2008). Modulation of L-serine levels in brains of mice lacking PICK1. Biol. Psychiatry 63, 997-1000. doi: 10.1016/j.biopsych.2007.09.025

Hoffman, H. E., Jiraskova, J., Ingr, M., Zvelebil, M., and Konvalinka, J. (2009). Recombinant human serine racemase: enzymologic characterization and comparison with its mouse ortholog. Protein Expr Purif. 63, 62-67. doi: 10.1016/j.pep.2008.09.003

Huang, Y. M., You, W., Caulkins, B. G., Dunn, M. F., Mueller, L. J., and Chang, C. E. (2016). Protonation states and catalysis: molecular dynamics studies of intermediates in tryptophan synthase. Prot. Sci. 25, 166-183. doi: $10.1002 /$ pro. 2709
Ishiwata, S., Umino, A., Balu, D. T., Coyle, J. T., and Nishikawa, T. (2015). Neuronal serine racemase regulates extracellular D-serine levels in the adult mouse hippocampus. J. Neural Transm. 122, 1099-1103. doi: 10.1007/s00702-015-1388-2

Jhee, K.-H., Yang, L.-,h., Ahmed, S. A., McPhie, P., Rowlett, R., and Miles, E. W. (1998). Mutation of an active site residue of tryptophan synthase ( $\beta$-serine 377) alters cofactor chemistry. J. Biol. Chem. 273, 11417-11422. doi: $10.1074 /$ jbc.273.19.11417

Jirásková-Vanícková, J., Ettrich, R., Vorlová, B., Hoffman, H. E., Lepšík, M., Jansa, P., et al. (2011). Inhibition of human serine racemase, an emerging target for medicinal chemistry. Curr. Drug Targets 12, 1037-1055. doi: 10.2174/138945011795677755

Karsten, W. E., Ohshiro, T., Izumi, Y., and Cook, P. F. (2005). Reaction of serine-glyoxylate aminotransferase with the alternative substrate ketomalonate indicates rate-limiting protonation of a quinonoid intermediate. Biochemistry 44, 15930-15936. doi: 10.1021/bi051407p

Karukurichi, K. R., de la Salud-Bea, R., Jahng, W. J., and Berkowitz, D. B. (2007) Examination of the new $\alpha-\left(2^{\prime} Z\right.$-fluoro $)$ vinyl trigger with lysine decarboxylase: the absolute stereochemistry dictates the reaction course. J. Am. Chem. Soc. 129, 258-259. doi: 10.1021/ja067240k

Kimura, H. (2000). Hydrogen sulfide induces cyclic AMP and modulates the NMDA receptor. Biochem. Biophys. Res. Commun. 267, 129-133. doi: 10.1006/bbrc. 1999.1915

Kimura, H. (2015). Signaling molecules: hydrogen sulfide and polysulfide. Antioxid. Redox Signal. 22, 362-376. doi: 10.1089/ars. 2014.5869

Kimura, Y., Mikami, Y., Osumi, K., Tsugane, M., Oka, J., and Kimura, H. (2013). Polysulfides are possible $\mathrm{H}_{2} \mathrm{~S}$-derived signaling molecules in rat brain. FASEB J. 27, 2451-2457. doi: 10.1096/fj.12-226415

Koutmos, M., Kabil, O., Smith, J. L., and Banerjee, R. (2010). Structural basis for substrate activation and regulation by cystathionine beta-synthase (CBS) domains in cystathionine $\beta$-synthase. Proc. Natl. Acad. Sci. U.S.A. 107, 20958-20963. doi: 10.1073/pnas.1011448107

Lee, S., Park, E. H., Ko, H. J., Bang, W. G., Kim, H. Y., Kim, K. H., et al. (2015). Crystal structure analysis of a bacterial aryl acylamidase belonging to the amidase signature enzyme family. Biochem. Biophys. Res. Commun. 467, 268-274. doi: 10.1016/j.bbrc.2015.09.177

Li, Z., Xing, Y., Guo, X., and Cui, Y. (2017). Development of an UPLC-MS/MS method for simultaneous quantitation of $11 \mathrm{D}$-amino acids in different regions of rat brain: application to a study on the associations of $\mathrm{D}$-amino acid concentration changes and Alzheimer's disease. J. Chromatogr. B 1058, 40-46. doi: 10.1016/j.jchromb.2017.05.011

Ma, T. M., Abazyan, S., Abazyan, B., Nomura, J., Yang, C., Seshadri, S., et al. (2013). Pathogenic disruption of DISC1-serine racemase binding elicits schizophrenia-like behavior via D-serine depletion. Mol. Psychiatry 18, 557-567. doi: 10.1038/mp.2012.97

Ma, T. M., Paul, B. D., Fu, C., Hu, S., Zhu, H., Blackshaw, S., et al. (2014). Serine racemase regulated by binding to stargazin and PSD-95. J. Biol. Chem. 289, 29631-29641. doi: 10.1074/jbc.M114.571604

McCune, C. D., Beio, M. L., Sturdivant, J. M., de la Salud-Bea, R., Darnell, B. M., and Berkowitz, D. B. (2017). Synthesis and deployment of an elusive fluorovinyl cation equivalent: access to quaternary $\alpha$-(1'-fluoro)vinyl amino acids as potential PLP enzyme inactivators. J. Am. Chem. Soc. 139, 14077-14089. doi: 10.1021/jacs.7b04690

McCune, C. D., Chan, S. J., Beio, M. L., Shen, W., Chung, W. J., Szczesniak, L. M., et al. (2016). "Zipped synthesis" by cross-metathesis provides a cystathionine $\beta$-synthase inhibitor that attenuates cellular $\mathrm{H}_{2} \mathrm{~S}$ levels and reduces neuronal infarction in a rat ischemic stroke model. ACS Cent. Sci. 2, 242-252. doi: 10.1021/acscentsci.6b00019

Metzler, C. M., Harris, A. G., and Metzler, D. E. (1988). Spectroscopic studies of quinonoid species from pyridoxal 5'-phosphate. Biochemistry 27, 4923-4933.

Meunier, C. N., Dallerac, G., Le Roux, N., Sacchi, S., Levasseur, G., Amar, M., et al. (2016). D-Serine and glycine differentially control neurotransmission during visual cortex critical period. PLOS ONE 11:e0151233. doi: 10.1371/journal.pone.0151233

Mileni, M., Garfunkle, J., DeMartino, J. K., Cravatt, B. F., Boger, D. L., and Stevens, R. C. (2009). Binding and inactivation mechanism of a humanized fatty 
acid amide hydrolase by $\alpha$-ketoheterocycle inhibitors revealed from co-crystal structures. J. Am. Chem. Soc. 131, 10497-10506. doi: 10.1021/ja902694n

Mizobuchi, T., Nonaka, R., Yoshimura, M., Abe, K., Takahashi, S., Kera, Y., et al. (2017). Crystal structure of a pyridoxal 5'-phosphate-dependent aspartate racemase derived from the bivalve mollusc Scapharca broughtonii. Acta Crystallogr. Section F Struct. Biol. Commun. 73, 651-656.

Mori, H. (2014). Mammalian serine racemase. Bio Industry 31, 17-23.

Mothet, J.-P. (2008). Brain-derived D-serine: from synthesis to function. Brain Mol. 105-129.

Mustafa, A. K., Ahmad, A. S., Zeynalov, E., Gazi, S. K., Sikka, G., Ehmsen, J. T., et al. (2010). Serine racemase deletion protects against cerebral ischemia and excitotoxicity. J. Neurosci. 30, 1413-1416. doi: 10.1523/JNEUROSCI.4297-09.2010

Nelson, D. L., Applegate, G. A., Beio, M. L., Graham, D. L., and Berkowitz, D. B. (2017). Human serine racemase structure/activity relationship studies provide mechanistic insight and point to position 84 as a hot spot for $\beta$-elimination function. J. Biol. Chem. 292, 13986-14002. doi: 10.1074/jbc.M117.777904

Phillips, R. S., Sundararaju, B., and Koushik, S. V. (1998). The catalytic mechanism of kynureninase from Pseudomonas fluorescens: evidence for transient quinonoid and ketimine intermediates from rapid-scanning stoppedflow spectrophotometry. Biochemistry 37, 8783-8789. doi: 10.1021/bi980066v

Pratt, R. F., and McLeish, M. J. (2010). Structural relationship between the active sites of $\beta$-lactam-recognizing and amidase signature enzymes: convergent evolution? Biochemistry 49, 9688-9697. doi: 10.1021/bi1012222

Raboni, S., Marchetti, M., Faggiano, S., Campanini, B., Bruna, S., Marchesani, F., et al. (2019). The energy landscape of human serine racemase. Front. Mol. Biosci. 5:112. doi: 10.3389/fmolb.2018.00112

Schell, M. J. (2004). The N-methyl D-aspartate receptor glycine site and D-serine metabolism: an evolutionary perspective. Phil. Trans. Royal Soc. Lond. Ser. B Biol. Sci. 359, 943-964. doi: 10.1098/rstb.2003.1399

Schneider, G., Kack, H., and Lindqvist, Y. (2000). The manifold of vitamin B6 dependent enzymes. Structure 8, R1-R6. doi: 10.1016/S0969-2126(00)00085-X

Shaw, J. P., Petsko, G. A., and Ringe, D. (1997). Determination of the structure of alanine racemase from Bacillus stearothermophilus at 1.9- $\AA$ resolution. Biochemistry 36, 1329-1342. doi: 10.1021/bi961856c

Smith, M. A., Mack, V., Ebneth, A., Moraes, I., Felicetti, B., Wood, M., et al. (2010). The structure of mammalian serine racemase: evidence for conformational changes upon inhibitor binding. J. Biol. Chem. 285, 12873-12881. doi: 10.1074/jbc.M109.050062

Strísovský, K., Jirásková, J., Barinka, C., Majer, P., Rojas, C., Slusher, B. S., et al. (2003). Mouse brain serine racemase catalyzes specific elimination of L-serine to pyruvate. FEBS Lett. 535, 44-48. doi: 10.1016/S0014-5793(02)03855-3

Strísovský, K., Jirásková, J., Mikulová, A., Rulísek, L., and Konvalinka, J. (2005). Dual substrate and reaction specificity in mouse serine racemase: identification of high-affinity dicarboxylate substrate and inhibitors and analysis of the beta-eliminase activity. Biochemistry 44, 13091-13100. doi: 10.1021/ bi051201o

Sun, S., and Toney, M. D. (1999). Evidence for a two-base mechanism involving tyrosine-265 from arginine-219 mutants of alanine racemase. Biochemistry 38 , 4058-4065. doi: 10.1021/bi982924t

Suzuki, M., Imanishi, N., Mita, M., Hamase, K., Aiso, S., and Sasabe, J. (2017). Heterogeneity of D-serine distribution in the human central nervous system. ASN Neuro 9:1759091417713905/1759091417713905. doi: $10.1177 / 1759091417713905$

Takahashi, S. (2009). Study on vitamin B2 and B6 enzymes involved in D-aspartate metabolism in eukaryote. Bitamin 83, 111-124.

Talukdar, G., Inoue, R., Yoshida, T., Ishimoto, T., Yaku, K., Nakagawa, T., et al. (2017). Novel role of serine racemase in anti-apoptosis and metabolism. Biochim. Biophys. Acta 1861, 3378-3387. doi: 10.1016/j.bbagen.2016.08.020

Toney, M. D. (2005). Reaction specificity in pyridoxal phosphate enzymes. Arch. Biochem. Biophys. 433, 279-287. doi: 10.1016/j.abb.2004.09.037

Toney, M. D., and Kirsch, J. F. (1993). Lysine 258 in aspartate aminotransferase: enforcer of the circe effect for amino acid substrates and the generalbase catalyst for the 1,3-prototropic shift. Biochemistry 32, 1471-1479. doi: $10.1021 / \mathrm{bi00057a010}$
Tu, Y., Kreinbring, C. A., Hill, M., Liu, C., Petsko, G. A., McCune, C. D., et al. (2018). Crystal structures of cystathionine $\beta$-synthase from Saccharomyces cerevisiae: one enzymatic step at a time. Biochemistry 57, 3134-3145. doi: 10.1021/acs.biochem.8b00092

Uda, K., Abe, K., Dehara, Y., Mizobata, K., Edashige, Y., Nishimura, R., et al. (2017). Triple serine loop region regulates the aspartate racemase activity of the serine/aspartate racemase family. Amino Acids 49, 1743-1754. doi: 10.1007/s00726-017-2472-8

Uda, K., Abe, K., Dehara, Y., Mizobata, K., Sogawa, N., Akagi, Y., et al. (2016). Distribution and evolution of the serine/aspartate racemase family in invertebrates. Amino Acids 48, 387-402. doi: 10.1007/s00726-0152092-0

Walsh, C. T. (1979). Enzymatic Reaction Mechanisms. San Francisco, CA: Freeman. Wang, C. Y., Ku, S. C., Lee, C. C., and Wang, A. H. (2012). Modulating the function of human serine racemase and human serine dehydratase by protein engineering. Protein Eng. Des. Sel. 25, 741-749. doi: 10.1093/protein/gzs078

Wang, W., and Barger, S. W. (2012). Cross-linking of serine racemase dimer by reactive oxygen species and reactive nitrogen species. J. Neurosci. Res. 90, 1218-1229. doi: 10.1002/jnr.22832

Weatherly, C. A., Du, S., Parpia, C., Santos, P. T., Hartman, A. L., and Armstrong, D. W. (2017). D-Amino acid levels in perfused mouse brain tissue and blood: a comparative study. ACS Chem. Neurosci. 8, 1251-1261. doi: 10.1021/acschemneuro.6b00398

Wolosker, H. (2007). NMDA receptor regulation by D-serine: new findings and perspectives. Mol. Neurobiol. 36, 152-164. doi: 10.1007/s12035-007-0038-6

Wolosker, H. (2011). Serine racemase and the serine shuttle between neurons and astrocytes. Biochim. Biophys. Acta 1814, 1558-1566. doi: 10.1016/j.bbapap.2011.01.001

Wolosker, H. (2018). The neurobiology of D-serine signaling. Adv. Pharmacol. 82, 325-348. doi: 10.1016/bs.apha.2017.08.010

Wolosker, H., Balu, D. T., and Coyle, J. T. (2016). The rise and fall of the Dserine-mediated gliotransmission hypothesis. Trends Neurosci. 39, 712-721. doi: $10.1016 /$ j.tins.2016.09.007

Wolosker, H., Dumin, E., Balan, L., and Foltyn, V. N. (2008). D-Amino acids in the brain: D-serine in neurotransmission and neurodegeneration. FEBS J. 275, 3514-3526. doi: 10.1111/j.1742-4658.2008.06515.x

Wolosker, H., and Mori, H. (2012). Serine racemase: an unconventional enzyme for an unconventional transmitter. Amino Acids 43, 1895-1904. doi: 10.1007/s00726-012-1370-3

Wolosker, H., Sheth, K. N., Takahashi, M., Mothet, J.-P., O, B. R. Jr., Ferris, C. D., et al. (1999). Purification of serine racemase: biosynthesis of the neuromodulator D-serine. Proc. Natl. Acad. Sci. U S A. 96, 721-725. doi: 10.1073/pnas.96.2.721

Xia, M., Zhu, S., Shevelkin, A., Ross, C. A., and Pletnikov, M. (2016). DISC1, astrocytes and neuronal maturation: a possible mechanistic link with implications for mental disorders. J. Neurochemistry 138, 518-524. doi: $10.1111 /$ jnc. 13663

Yamauchi, T., Goto, M., Wu, H. Y., Uo, T., Yoshimura, T., Mihara, H., et al. (2009). Serine racemase with catalytically active lysinoalanyl residue. J. Biochem. 145, 421-424. doi: 10.1093/jb/mvp010

Yoshimura, T., and Ito, T. (2014). Vitamin $\mathrm{B}_{6}$-dependent enzymes involved in D-serine metabolism: serine racemase and D-serine dehydratase. Bitamin $88,462-468$

Conflict of Interest Statement: The authors declare that the research was conducted in the absence of any commercial or financial relationships that could be construed as a potential conflict of interest.

Copyright (๑) 2019 Graham, Beio, Nelson and Berkowitz. This is an open-access article distributed under the terms of the Creative Commons Attribution License (CC $B Y)$. The use, distribution or reproduction in other forums is permitted, provided the original author(s) and the copyright owner(s) are credited and that the original publication in this journal is cited, in accordance with accepted academic practice. No use, distribution or reproduction is permitted which does not comply with these terms. 